\title{
Evaluation of detailed aromatic mechanisms (MCMv3 and MCMv3.1) against environmental chamber data
}

\author{
C. Bloss ${ }^{1}$, V. Wagner ${ }^{1}$, A. Bonzanini ${ }^{1}$, M. E. Jenkin ${ }^{2}$, K. Wirtz ${ }^{3}$, M. Martin-Reviejo ${ }^{3}$, and M. J. Pilling ${ }^{1}$ \\ ${ }^{1}$ School of Chemistry, University of Leeds, Leeds LS2 9JT, UK \\ ${ }^{2}$ Imperial College London, Silwood Park, Ascot, Berkshire SL5 7PY, UK \\ ${ }^{3}$ Centro de Estudios Ambientales del Mediterraneo, C. Charles R. Darwin 14, 46980 Paterna, Spain
}

Received: 27 July 2004 - Published in Atmos. Chem. Phys. Discuss.: 24 September 2004

Revised: 20 December 2004 - Accepted: 4 February 2005 - Published: 1 March 2005

\begin{abstract}
A high quality dataset on the photo-oxidation of benzene, toluene, $p$-xylene and 1,3,5-trimethylbenzene has been obtained from experiments in the European Photoreactor (EUPHORE), a large outdoor environmental reaction chamber. The experiments were designed to test sensitive features of detailed aromatic mechanisms, and the dataset has been used to evaluate the performance of the Master Chemical Mechanism Version 3 (MCMv3). An updated version (MCMv3.1) was constructed based on recent experimental data, and details of its development are described in a companion paper. The MCMv3.1 aromatic mechanisms have also been evaluated using the EUPHORE dataset. Significant deficiencies have been identified in the mechanisms, in particular: 1) an over-estimation of the ozone concentration, 2) an under-estimation of the NO oxidation rate, 3) an under-estimation of $\mathrm{OH}$. The use of MCMv3.1 improves the model-measurement agreement in some areas but significant discrepancies remain.
\end{abstract}

\section{Introduction}

Ground-level ozone is produced by the photo-oxidation of volatile organic compounds (VOC) in the presence of nitrogen oxides $\left(\mathrm{NO}_{\mathrm{x}}\right)$. Houweling et al. (1998) have estimated that aromatic species contribute about $10 \%$ to the global anthropogenic non-methane VOC emissions, the major source being car exhaust and with a significant contribution from solvent usage. Because of their high ozone creation potentials (Derwent et al., 1998), their contribution to ozone production on a global scale is likely to be proportionately much greater than that which would be estimated based on mass emissions alone. Trajectory model calculations show that for an air mass typical of northwest Europe about one third of the

Correspondence to: M. J. Pilling

(m.j.pilling@leeds.ac.uk) ozone production is caused by aromatic hydrocarbons (Derwent et al., 1996). Aromatics are also aerosol precursors and it is believed that they significantly contribute to the generation of secondary organic aerosols (Forstner et al., 1997; Calvert et al., 2002)

Photochemical ozone and particulate matter formation are major priorities of the EU air quality policy in the coming decade (CAFE, 2001). Elevated concentrations of ozone have been known for a long time now to have adverse effects on human health and vegetation (PORG, 1997). Recent research activities provide also increasing evidence that fine particulate matter has deleterious effects on human health and is causing premature deaths (Finlayson-Pitts and Pitts, 1997, and references therein). Based on these research results the EU legislations classify fine aerosols $\left(\mathrm{PM}_{10}\right)$ now as one of 12 key air pollutants for which target values are defined to achieve necessary reduction in atmospheric concentrations and improvements in air quality (AQS, 2000).

Photochemical mechanisms are used in air quality modelling to assess the importance of the emission of air pollutants on the formation of ozone. They are applied, for example, for the calculation of photochemical ozone creation potentials (POCP) for VOC that assist policy makers in defining realistic and cost-efficient pollution control strategies (Derwent et al., 1996). Thus, a detailed understanding of the oxidation mechanisms of aromatics in the atmosphere is a prerequisite for assessing the impact of aromatic emissions on air quality.

For the aromatics that have the greatest effect on air quality, such as benzene, toluene, trimethylbenzenes, and xylenes, the rate coefficients for the $\mathrm{OH}$-radical reaction are known with an uncertainty of about 20-25\% (Calvert et al., 2002). The reaction of an aromatic with $\mathrm{OH}$ can either result in ring-retaining products or in an opening of the aromatic ring. Primary products of the ring-opening routes are carbonyl compounds, many of them highly polar and photolabile, which makes quantitative measurements a major

(C) 2005 Author(s). This work is licensed under a Creative Commons License. 
challenge. Owing to these difficulties the mass balance for carbon from product analysis is in all cases less than $70 \%$ and typically less than 50\% (Calvert et al., 2002). Even yields of major reaction products, reported by different studies, in many cases cover a range of more than a factor of two, reflecting great experimental uncertainties (Atkinson et al., 1989; Klotz et al., 1998; Volkamer et al., 2001, and references therein).

Despite our fragmentary understanding of aromatic photooxidation, the available kinetic and mechanistic data have been condensed into a Master Chemical Mechanism now including the photo-oxidation of 18 aromatics (http://www. chem.leeds.ac.uk/Atmospheric/MCM/mcmproj.html). The protocol for the development of the aromatic mechanisms of MCMv3 is described by Jenkin et al. (2003) and reflects the state of knowledge in early 2001. Although there has been much work carried out to elucidate the details of aromatic oxidation over the past two decades, the mechanisms remain highly speculative, particularly because of the limited knowledge of the chemistry in the ring-opening routes.

Therefore it is not surprising that comparisons of the aromatic mechanisms of MCMv1, MCMv2 and MCMv3 with smog-chamber data reveal large deviations for ozone production as well as the decay of the parent aromatic (Liang and Jacobson, 2000; Wagner et al., 2003). The observed discrepancies indicate shortcomings in the mechanisms concerning both the production of $\mathrm{HO}_{\mathrm{x}}$ radicals and the $\mathrm{NO}$ to $\mathrm{NO}_{2}$ transformation.

These studies imply that for a reliable assessment of the impact of aromatic emissions on regional ozone formation and on secondary aerosol, further improvement of the MCM is required. Traditionally, complex photo-oxidation mechanisms of VOC are tested with experiments carried out in large reaction vessels, so called smog-chambers (Carter et al., 1995). Compared to ambient simulations this approach has the advantage that a single component system can be investigated under well-defined conditions that are not complicated by meteorological and transport effects. Unfortunately the use of smog-chamber data has its own set of difficulties. In particular heterogeneous processes occurring on the walls of the chambers can have a significant impact on the chemical system under observation (Killus and Whitten, 1990; Carter, 1995; Dodge, 2000), and loss of chemicals to the chamber walls may be important. If smog-chamber data are used for the evaluation of chemical mechanisms these chamber-related effects need to be quantified and represented by an auxiliary mechanism.

To evaluate the aromatic mechanisms of MCMv3 a set of smog-chamber experiments was carried out during two campaigns (EXACT-1 and EXACT-2) at EUPHORE as part of the EXACT project (Effects of the oXidation of Aromatic Compounds in the Troposphere). The evaluation procedure focused on four representatives of the class of aromatic compounds: benzene, toluene, $p$-xylene and 1,3,5-trimethylbenzene (1,3,5-TMB). The objectives of the
EXACT-1/2 campaigns were to deliver a comprehensive evaluation dataset that enables us to develop a coherent picture of the shortcomings in the aromatic mechanisms and to test specific mechanistic details, such as photolysis rates of ring-opened products, yields of major reaction channels and the carbon balance. We have used models to tailor the experimental conditions so that the experiments deliver a maximum of information for the evaluation of the aromatic mechanism. To take chamber-related effects into account an auxiliary mechanism was constructed and tested against chamber characterization experiments with ethene.

In this paper we describe the dataset for aromatic model evaluation that was obtained in the two EXACT campaigns and we present results of the evaluation of aromatic mechanisms of the MCMv3. Measures of model performance are discussed and trends within the set of aromatics are analysed. Based on results from the evaluation experiments, results from the kinetic workpackages of the EXACT project and newly available literature data the aromatic mechanisms were updated to the version MCMv3.1. The performance of these mechanisms is also compared to the evaluation experiments. A detailed discussion of the mechanism development itself is presented in a companion publication (Bloss et al., 2005).

\section{Methods}

\subsection{Selection of aromatics}

We have selected four aromatic compounds for the evaluation experiments considering two major criteria: 1) the proportion of the ring-opening routes in the aromatic- $\mathrm{OH}$ adduct channel and 2) the complexity of the mechanism. The yields of ring-opening routes of the reaction of the aromatic-OH adduct with $\mathrm{O}_{2}$ increase with the number of methyl substituents (Smith et al., 1998, 1999). A correlation or anticorrelation between the number of methyl groups of the aromatic and the model-experiment discrepancy for a certain parameter, e.g. the ozone production, would give an indication whether the model shortcomings are located in the ringopening or ring-retaining routes of the mechanism. The symmetry of an aromatic is linked to the number of intermediates formed during the photo-oxidation: the higher the symmetry of the compound, the lower the number of reaction products and the less complex the mechanism. Based on these considerations we have chosen benzene, toluene, $p$-xylene and $1,3,5-\mathrm{TMB}$ as a series of aromatics with increasing number of methyl groups and highest possible symmetry.

\subsection{Target species}

While EUPHORE is highly instrumented the selection of species for measurement is necessarily limited, and only a selection of reactants and intermediates of the aromatic systems could be quantified in the EXACT campaigns. We focused 
on key compounds that are classified into three groups according to their importance for the assessment of the model performance.

The first group contains the parent aromatic, $\mathrm{O}_{3}, \mathrm{NO}$ and $\mathrm{NO}_{2}$. The concentration time profiles of these compounds deliver crucial information on the ozone production and the oxidative capacity in the system. To ensure high data quality the aromatic and ozone were measured with two independent methods, FTIR/GC and UV/FTIR, respectively. $\mathrm{NO}_{2}$ was measured with a direct method (DOAS), as catalytic converters linked to chemiluminesence instruments are known to be prone to interferences. The details of all the experimental methods used are discussed in Sect. 3.

The second group contains compounds that deliver important information on the $\mathrm{NO}_{\mathrm{y}}$ budget, $\mathrm{HO}_{\mathrm{x}}$ production or the branching ratios for major reaction routes: $\mathrm{HNO}_{3}$, PAN, HCHO, glyoxal, methylglyoxal, cresol isomers and benzaldehyde. $\mathrm{HNO}_{3}$ and PAN are crucial components of the $\mathrm{NO}_{\mathrm{y}}$ budget and play an important role for long-range transport of oxidised nitrogen in the atmosphere. HCHO, glyoxal and methylglyoxal have been identified as major radical sources in the aromatic oxidation mechanisms (Wagner et al., 2003). Compounds of the second group occur in concentrations during the course of a smog-chamber experiment that are high enough to be quantified. But owing to more demanding measurement techniques, uncertainties of these measurements are considerably higher than for the compounds of the first class.

The third group of compounds contains reaction products, such as butenedial, 4-oxo-2-pentenal, $\alpha$-angelica lactone, furanones and epoxide type compounds. These compounds are formed in the ring opening channels and potentially provide key information on those channels, on the carbon budget and on radical production in the aromatic systems. However they are extremely difficult to quantify because of their high reactivity and low concentrations.

\subsection{Experimental design}

Smog-chamber experiments coupled with sensitivity analysis, have shown that the sensitivity of the ozone production to model parameters (e.g. rate coefficients, product yields, photolysis rates) is highest at low $\mathrm{VOC} / \mathrm{NO}_{\mathrm{x}}$ ratios, that means in a chemical domain where the ozone production is limited by the availability of VOC (Dodge, 2000; Wagner et al., 2003). For that reason, experiments at low $\mathrm{VOC} / \mathrm{NO}_{\mathrm{x}}$ ratios are particularly suited to the identification of shortcomings of the ozone chemistry in models. On the other hand, these conditions are not typical of atmospheric conditions that prevail in Southern Europe where the ozone production can be $\mathrm{NO}_{\mathrm{x}}$ limited (Solomon et al., 2000). Therefore we decided to carry out evaluation experiments at both, low and high $\mathrm{VOC} / \mathrm{NO}_{\mathrm{x}}$ ratios. Unfortunately the VOC limited region is experimentally not accessible for aromatics with very high reactivities: the concentration of the aromatic is either too low for ac- curate measurements or the $\mathrm{NO}_{\mathrm{x}}$ concentration is so high $(>500 \mathrm{ppb})$ that reaction pathways which are inoperative under atmospheric conditions become important (Volkamer et al., 2002).

With the aid of models we have carefully chosen the initial conditions for the evaluation experiments considering all technical constraints and trying to come as close as possible to atmospheric conditions (Wagner et al., 2003). These simulations show that it is possible to carry out experiments in the $\mathrm{VOC}$ and $\mathrm{NO}_{\mathrm{x}}$ limited regimes for benzene and toluene, whereas for $p$-xylene and 1,3,5-TMB only the $\mathrm{NO}_{\mathrm{x}}$ limited regime is experimentally accessible. Ozone isopleth plots showing the modelled maximum ozone concentration as a function of initial aromatic and $\mathrm{NO}_{\mathrm{x}}$ concentrations are available as supplementary information.

In remote and rural areas of Europe and North America $\mathrm{NO}_{\mathrm{x}}$ concentrations are usually lower than $10 \mathrm{ppb}$ (Finlayson-Pitts and Pitts, 1999). To test the model performance under these conditions a new experimental modus was employed: over the whole course of the experiment a $\mathrm{NO} / \mathrm{NO}_{2} / \mathrm{HONO}$ mixture was injected into the chamber controlled by a feedback system that kept the $\mathrm{NO}_{\mathrm{x}}$ concentration at about 9 ppb. These $\mathrm{NO}_{\mathrm{x}}$ replacement runs were only carried out for toluene and 1,3,5-TMB.

\subsection{Model simulations of smog-chamber experiments}

The initial concentrations used in the simulations are those measured immediately before the chamber was exposed to sunlight, and are listed in Table 1. In most cases the initial HONO concentration could not be measured but was estimated as discussed below in Sect. 4.1. The temperature and humidity of the chamber were continuously monitored during the experiments and these values are used in the models. Chamber humidity was low and typical water mixing ratios of 40-70 ppm were observed. The measured photolysis rate for $\mathrm{NO}_{2}$ is available and for all other photolysis processes calculated rates were used with scaling factors applied to account for the transmission of the chamber walls, backscattering from the chamber floor and cloud cover. The variations from day to day and during the experiments resulting from cloud cover are accounted for by considering the difference between measured and calculated clear sky $\mathrm{J}\left(\mathrm{NO}_{2}\right)$ at any given time during the experiments. This variable scaling factor, f1, is applied to all photolysis rates in addition to a factor, $\mathrm{f} 2$, designed to account for wall and cloud transmission effects, which will be different for different species dependent on their absorption spectrum. In a previous chamber dataset (22 October 1997) the photolysis rates for $\mathrm{O}_{3}$, $\mathrm{HCHO}, \mathrm{HONO}$ were available in addition to $\mathrm{J}\left(\mathrm{NO}_{2}\right)$, and for these species the applied scaling factors, $\mathrm{f} 2$, are based on the deviation between their measured and calculated photolysis rates, normalised by the deviation seen for $\mathrm{NO}_{2}$. For all other photolysis rates the average value of these factors is used. 
Table 1. Initial conditions used in simulations, concentrations measured before opening chamber to sunlight.

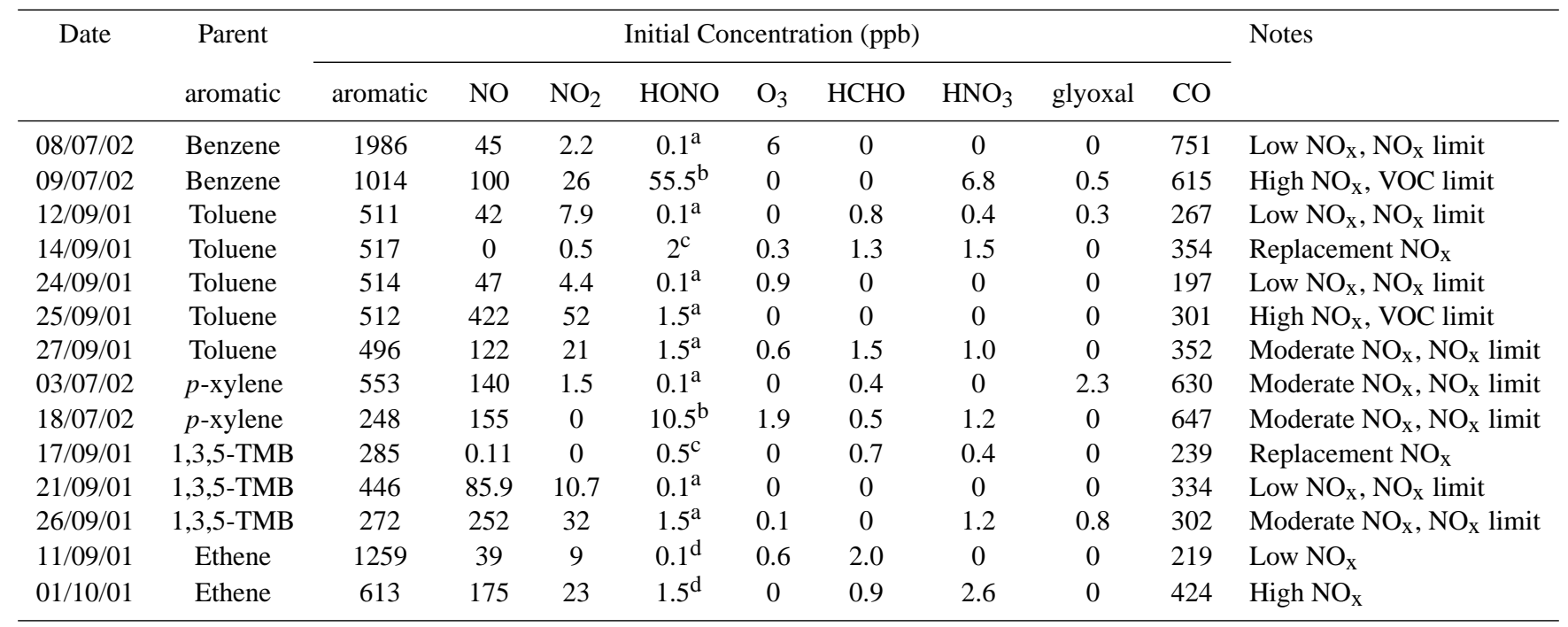

a Estimated by consideration of simulations of ethene experiments as described in text.

b Measured concentration.

${ }^{\mathrm{c}}$ Calculated from known addition of $\mathrm{HONO}, \mathrm{NO}, \mathrm{NO}_{2}$, gas mixture.

d Chosen to best represent early time dependent behaviour of observed concentrations as described in text.

During the experiments a certain amount of air from the chamber is lost through small leaks and withdrawal of air samples for analysis; clean air is added to compensate for this and some dilution of the reactants and products occurs as a result. To measure the dilution rate $\mathrm{SF}_{6}$ was added to the reaction mixture as an inert tracer in each experiment and its concentration was monitored by FTIR. The average calculated loss rate of $\mathrm{SF}_{6}$ over the course of each experiment is used as the dilution rate applied to all stable species in the simulations. Dilution rates are in the range (1.22) $\times 10^{-5} \mathrm{~s}^{-1}$.

One of the most controversial issues of mechanism evaluation with smog-chamber data is the influence of chamberdependent reactions on the reactivity of the chemical system under observation. There are three major groups of processes that contribute to chamber effects: 1) the introduction of free radicals through wall reactions, 2) the adsorption/desorption of $\mathrm{NO}_{\mathrm{y}}$ species on/from the walls and 3) off-gassing of organics from the walls that convert $\mathrm{OH}$ to $\mathrm{HO}_{2}$ and add to ozone production in the system (Killus and Whitten, 1990).

An auxiliary mechanism that considers these chamber related effects has been constructed and the relevant reactions and associated rate coefficients are listed in Table 2. Where data from EUPHORE characterisation experiments are not available, literature data adapted to EUPHORE conditions are taken, and upper and lower limits to these rates have been assigned in order to estimate the maximum impact the auxiliary mechanism may have on the simulations. To test the performance of the auxiliary mechanism two chamber characterisation experiments with ethene were carried out to cover both the high $\mathrm{VOC} / \mathrm{NO}_{\mathrm{x}}$ and the low $\mathrm{VOC} / \mathrm{NO}_{\mathrm{x}}$ regimes. Ethene was chosen as the VOC with a simple, well understood, photo-oxidation mechanism that comes closest to the reactivity of the aromatics. The model-experiment discrepancies for key reactants and reaction products, such as ethene, $\mathrm{O}_{3}, \mathrm{NO}$, and $\mathrm{NO}_{2}$, are taken as a measure for wall-dependent reactions. The auxiliary mechanism has been tuned to fit the model-experiment discrepancies of the ethene experiments and the resulting auxiliary mechanism was then taken to describe the wall effects in simulations of the aromatic systems.

\subsection{Measures of model performance}

For evaluation of the aromatic mechanisms the most important measures of the model performance are those that relate to the ability of the model to simulate the ozone production and the oxidative capacity in the system.

The production of ozone in the presence of reactive organic species is a result of the conversion of $\mathrm{NO}$ to $\mathrm{NO}_{2}$ by reaction with peroxy radicals. These processes do not consume ozone, and therefore the subsequent photolysis of $\mathrm{NO}_{2}$ to form $\mathrm{O}\left({ }^{3} \mathrm{P}\right)$ atoms acts as a net ozone source. The simplest measure of model performance concerning ozone production is the error in the maximum ozone concentration reached, and this can be evaluated either at the time of the observed maximum concentration, or as the difference between the modelled and measured maxima unpaired in time. While 
Table 2. Auxiliary mechanism constructed to consider chamber related reactions.

\begin{tabular}{|c|c|c|c|c|}
\hline Process & Nominal rate & Lower limit & $\begin{array}{l}\text { Upper } \\
\text { limit }\end{array}$ & Notes \\
\hline $\begin{array}{c}\mathrm{NO}_{2}=0.5 \mathrm{HONO}+0.5 \\
\mathrm{wHNO}_{3}\end{array}$ & $1.15 \mathrm{e}-5 \mathrm{~s}^{-1}$ & $0.7 \mathrm{e}-5 \mathrm{~s}^{-1}$ & $1.6 \mathrm{e}-5 \mathrm{~s}^{-1}$ & EUPHORE characterisation \\
\hline $\mathrm{wHNO}_{3}+\mathrm{hv}=\mathrm{OH}+\mathrm{NO}_{2}$ & $\mathrm{~J}_{\mathrm{HNO} 3}$ & 0 & $2 * \mathrm{~J}_{\mathrm{HNO} 3}$ & \\
\hline $\begin{array}{c}\mathrm{hv}=\mathrm{NO}_{2} \\
\text { (Light induced } \mathrm{NO}_{2} \text { off- } \\
\text { gassing) }\end{array}$ & $\begin{array}{c}0.1^{*} \mathrm{~J}_{\mathrm{NO} 2} \\
\mathrm{ppb} \mathrm{s}^{-1}\end{array}$ & $\begin{array}{c}0.025^{*} \mathrm{~J}_{\mathrm{NO} 2} \\
\mathrm{ppb} \mathrm{s}^{-1}\end{array}$ & $\begin{array}{l}0.2^{*} \mathrm{~J}_{\mathrm{NO} 2} \\
\mathrm{ppb} \mathrm{s}^{-1}\end{array}$ & $\begin{array}{l}\text { Limits are } 270 \text { and } 330 \mathrm{~K} \\
\text { values for UNC chamber } \\
\text { (Carter and Lurmann 1991) } \\
\text { nominal is average value }\end{array}$ \\
\hline $\mathrm{N}_{2} \mathrm{O}_{5}=2 \mathrm{wHNO}_{3}$ & $3 e-5 s^{-1}$ & $1.3 \mathrm{e}-5 \mathrm{~s}^{-1}$ & $4.7 \mathrm{e}-5 \mathrm{~s}^{-1}$ & $\begin{array}{l}\text { Upper limit as measured } \\
\text { by.(Tuazon et al. 1983) for } \\
38001 \text { Teflon chamber, } \\
\text { lower limit scaling for S/V. }\end{array}$ \\
\hline $\mathrm{N}_{2} \mathrm{O}_{5}+\mathrm{H}_{2} \mathrm{O}=2 w_{\mathrm{HNO}}$ & $\begin{array}{l}6.5 \mathrm{e}-20 \\
\mathrm{~cm}^{3} \mathrm{~s}^{-1}\end{array}$ & $\begin{array}{l}1.1 \mathrm{e}-23 \\
\mathrm{~cm}^{3} \mathrm{~s}^{-1}\end{array}$ & $\begin{array}{l}1.3 \mathrm{e}-19 \\
\mathrm{~cm}^{3} \mathrm{~s}^{-1}\end{array}$ & $\begin{array}{l}\text { Lower limit as (Tuazon et } \\
\text { al. 1983) scaled for S/V, } \\
\text { upper limit as used in UNC } \\
\text { mechanism } 1999 .\end{array}$ \\
\hline $\mathrm{OH}=\mathrm{HO}_{2}$ & $8.4 \mathrm{~s}^{-1}$ & $4.2 \mathrm{~s}^{-1}$ & $12.5 \mathrm{~s}^{-1}$ & $\begin{array}{l}\text { Background reactivity, } \\
\text { upper limit as UNC } \\
\text { chamber, lower limit as } \\
\text { SAPRC chamber (Carter } \\
\text { and Lurmann 1991) }\end{array}$ \\
\hline $\mathrm{O}_{3}=\mathrm{wO}_{3}$ & $3 e-6 s^{-1}$ & $1.5 \mathrm{e}-6 \mathrm{~s}^{-1}$ & $6 e-6 s^{-1}$ & $\begin{array}{c}\mathrm{O}_{3} \text { wall loss from } \\
\text { EUPHORE characterisation }\end{array}$ \\
\hline $\mathrm{HNO}_{3}=\mathrm{wHNO}_{3}$ & $8.2 \mathrm{e}-5 \mathrm{~s}^{-1}$ & $4.1 \mathrm{e}-5 \mathrm{~s}^{-1}$ & $1.6 \mathrm{e}-4 \mathrm{~s}^{-1}$ & $\begin{array}{c}\mathrm{HNO}_{3} \text { wall loss from } \\
\text { EUPHORE characterisation }\end{array}$ \\
\hline Initial HONO & $0.5 \mathrm{ppb}$ & $0 \mathrm{ppb}$ & $1.0 \mathrm{ppb}$ & \\
\hline
\end{tabular}

the former approach is the more stringent, the latter can be used to give a good measure of the overall ozone yield of the simulation independent of timing (Carter and Lurmann, 1991).

The rate of change of the difference in ozone and NO concentrations $\left(\mathrm{d}\left(\left[\mathrm{O}_{3}\right]-[\mathrm{NO}]\right) / \mathrm{dt}\right)$ can be shown to be equal to the rate of consumption of $\mathrm{NO}$ by reaction with species other than $\mathrm{O}_{3}$, and the major such process is conversion of $\mathrm{NO}$ to $\mathrm{NO}_{2}$ by reaction with peroxy radicals. Therefore the rate, $\mathrm{d}\left(\left[\mathrm{O}_{3}\right]-[\mathrm{NO}]\right) / \mathrm{dt}$ is closely related to the processes responsible for the production of ozone in photosmog systems and can be used as a definition of reactivity both early in the experiment when the NO concentration is high, and later when most of the NO has been consumed and significant amounts of $\mathrm{O}_{3}$ are being formed. Carter and Lurmann (1991) have found the average value of $\mathrm{d}\left(\left[\mathrm{O}_{3}\right]-[\mathrm{NO}]\right) / \mathrm{dt}$ evaluated for the first half of the time taken to attain maximum experimental ozone concentration to be a good measure for the overall timing of model simulations, and this parameter is referred to as the 'NO oxidation rate'.
For all the aromatics studied, it was found that the modelled $\mathrm{OH}$ concentration was insufficient to account for the removal of the primary aromatic. The oxidative capacity of the aromatic systems under chamber conditions is determined by the concentration of $\mathrm{OH}$ radical, as this is the dominant oxidant. Therefore the amount of $\mathrm{OH}$ production missing from the mechanism is an important measure of the model performance, and was calculated using a model where an arbitrary $\mathrm{OH}$ source was added to the mechanism. The rate of $\mathrm{OH}$ production from this source was constrained to reproduce the observed loss of the primary aromatic. The 'missing $\mathrm{OH}^{\prime}$ ' is then defined as the total amount of $\mathrm{OH}$ produced by this arbitrary source over the course of the experiment. This value should be compared to the new $\mathrm{OH}$ produced by all the other processes included in the mechanism which was calculated by considering the overall radical budget as described in detail by Wagner et al. (2003).

The ability of the model to simulate production of other key product species such as PAN, $\mathrm{HNO}_{3}$, formaldehyde etc. is evaluated as for ozone, by considering the error in maximum concentration reached, irrespective of timing. 
Table 3. Instrumentation used in EUPHORE chambers.

\begin{tabular}{|c|c|c|c|c|}
\hline Instrument & $\begin{array}{l}\text { Compounds/ } \\
\text { Parameters }\end{array}$ & Sampling Method & Analysis Type & Notes \\
\hline $\begin{array}{l}\text { FTIR Magna 550 } \\
\text { F }\end{array}$ & $\overline{\mathrm{VOC}, \mathrm{O}_{3},}$ & $\begin{array}{l}\text { In-situ White-type } \\
\text { mirrors optical path } \\
\quad=553 \mathrm{~m}\end{array}$ & On-line & \\
\hline HPLC-UV/FLD & $\begin{array}{l}\text { Phenol, cresols, } \\
\text { catechols }\end{array}$ & Stripping technique & $\begin{array}{c}\text { Variable sampling } \\
\text { times }\end{array}$ & $\begin{array}{l}\text { Detection limits below } \\
\text { ppb }\end{array}$ \\
\hline $\begin{array}{l}\text { Ozone Monitor } \\
\text { ML9810 }\end{array}$ & $\mathrm{O}_{3}$ & \multirow{6}{*}{ PTFE Teflon ${ }^{\circledR}$ line } & \multirow{3}{*}{$\begin{array}{l}\text { On-line / } 1 \mathrm{~min} \\
\text { averages }\end{array}$} & \\
\hline $\begin{array}{c}\mathrm{NO}_{\mathrm{x}} \text { Monitors } \\
\text { ML 9841A and Eco } \\
\text { Physics CL D770 AL }\end{array}$ & $\mathrm{NO}, \mathrm{NO}_{2}$ & & & \\
\hline CO Monitor & $\mathrm{CO}$ & & & Detection Limit 20ppb \\
\hline $\begin{array}{c}\text { GC-FID/ECD } \\
\text { HP6890 }\end{array}$ & VOC, PAN & & $\begin{array}{c}\text { Sampling loop / } 20 \\
\text { min }\end{array}$ & $\begin{array}{c}\text { Detection limit } \\
\text { butenedial } 2 \mathrm{ppb}\end{array}$ \\
\hline $\begin{array}{l}\text { GC- Schmitt PAN- } \\
\text { Analyser }\end{array}$ & $\begin{array}{l}\text { PAN, Methyl } \\
\text { glyoxal }\end{array}$ & & $\begin{array}{l}\text { Sampling loop / } 10 \\
\min \end{array}$ & $\begin{array}{c}\text { Analysis of HONO also } \\
\text { possible }\end{array}$ \\
\hline Hygrometer & Humidity & & $\begin{array}{c}\text { Dew-point mirror / } \\
1 \text { min averages }\end{array}$ & \\
\hline DOAS & $\begin{array}{c}\mathrm{NO}_{2}, \mathrm{HCHO}, \\
\text { HONO, Glyoxal }\end{array}$ & $\begin{array}{c}\text { In-situ White-type } \\
\text { mirrors, variable } \\
\text { optical path }\end{array}$ & $\begin{array}{l}\text { Alternate two } \\
\text { spectral ranges }\end{array}$ & \\
\hline GCXGC HP6890 & VOC, Carbonyls & $\begin{array}{l}\text { Cryogenic } \\
\text { enrichment }\end{array}$ & $30 \mathrm{~min}$ & \\
\hline $\begin{array}{c}\mathrm{OH} / \mathrm{HO}_{2}-\mathrm{LIF} \\
\text { system }\end{array}$ & $\begin{array}{c}\mathrm{OH} \text { and } \mathrm{HO}_{2} \\
\text { Alternate mode }\end{array}$ & Gas expansion & $\begin{array}{c}\text { Quantification } \\
\text { against calibration } \\
\text { source }\end{array}$ & $\begin{array}{c}\text { OH only during } \\
\text { EXACT-1 }\end{array}$ \\
\hline Filter radiometer & $\mathrm{J}\left(\mathrm{NO}_{2}\right)$ & $4 \pi s \mathrm{r}$ & $1 \mathrm{~min}$ & Actinic flux \\
\hline
\end{tabular}

\section{Experimental}

The comprehensive dataset for aromatic model evaluation was obtained during two measurement campaigns at the large-volume outdoor smog chamber EUPHORE, located in Valencia, Spain. The full details concerning the operation of the chamber and associated instruments are discussed elsewhere (Becker, 1996), and a brief description of the features particularly relevant to obtaining the aromatic dataset is given below.

The EUPHORE facility consists of two FEP foil hemispherical chambers with approximate volume $200 \mathrm{~m}^{3}$, the transmission of both visible and UV light through the chamber walls is high (85-90\% for wavelengths $500-320 \mathrm{~nm}$, and around $75 \%$ at $290 \mathrm{~nm}$ ). The aluminium floor panels are covered with FEP foil and are water cooled to reduce solar heating of the chamber and maintain realistic atmospheric temperatures during experimental runs. The chambers are supplied with hydrocarbon and $\mathrm{NO}_{\mathrm{y}}$-free, dry air by use of an air-drying and purification system that reduces the back- ground concentration of non-methane hydrocarbons to levels below $0.3 \mu \mathrm{g} \mathrm{m}^{-3}$. Homogeneous mixing in the chamber is achieved with two mixing fans of $67 \mathrm{~m}^{3} \mathrm{~min}^{-1}$ air throughput running throughout the experiment. Aromatic hydrocarbons were injected into the chamber from a calibrated syringe and NO was introduced from a gas cylinder through a Teflon transfer line.

The experiments described in this work were carried out in Chamber A, and a summary of the instrumentation used is given in Table 3. Two White-type multi reflection cells are mounted in the chamber; one White system consists of gold-coated mirrors and is coupled to an FTIR interferometer (NICOLET Magna 550, MCT-B detector), operated at an absorption path length of $326.8 \mathrm{~m}$. The spectra were derived from the co-addition of 570 interferograms, the spectral resolution was $1 \mathrm{~cm}^{-1}$ and the time resolution was $10 \mathrm{~min}$. The FTIR spectra were analysed by subtracting individual reference spectra to obtain the concentration of those compounds. This system was used to obtain the concentration-time profiles of the parent aromatic and ozone, crucial measurements 
for the evaluation of model performance concerning ozone production and oxidative capacity. Concentrations of $\mathrm{HNO}_{3}$ and $\mathrm{HCHO}$ were also available from the FTIR measurements and these deliver important information on the $\mathrm{NO}_{y}$ and $\mathrm{HO}_{\mathrm{x}}$ production, respectively.

The other White system is actively laser aligned, equipped with UV-enhanced aluminium coated mirrors coupled to a DOAS spectrometer (f/6.9 Czerny Turner spectrograph; Acton 500; focal length $0.5 \mathrm{~m}$ ) and operated at an absorption path length of $386 \mathrm{~m}$. DOAS was used to measure concentrations of $\mathrm{NO}_{2}, \mathrm{HONO}$ and the products $\mathrm{HCHO}$ and glyoxal.

The chamber is also equipped with a thermocouple PT100 to measure air temperature, and two filter radiometers for measuring $\mathrm{J}\left(\mathrm{NO}_{2}\right)$; one to measure direct sunlight, the other facing towards the chamber floor and measuring reflected light. Sampling ports in the floor panels connect to various instruments via PTFE Teflon lines: an ozone monitor (Monitor Labs), two $\mathrm{NO}_{\mathrm{x}}$ monitors (ML9841A and Eco physics CLD770 AL), a hygrometer, GC-FID/ECD (HP6890) for measuring PAN and VOC concentrations, and GC-Schmitt PAN Analyser for PAN and methylglyoxal. During the EXACT campaigns an additional instrument was used for comprehensive gas chromatography (GCXGC) and measured carbonyl compounds (Hamilton et al., 2003).

The parent aromatic and ozone concentrations were measured with two independent methods, FTIR/GC and UV/FTIR, respectively. For the aromatic, reasonable agreement between the two techniques was achieved and the model-measurement comparison was carried out using the FTIR data. In most cases the FTIR and the UV monitor gave consistent measurements for ozone, and the UV measurements were used for comparison with the simulations. However, in the two $p$-xylene experiments the maximum concentrations observed with the UV monitor were significantly higher than measured by FTIR and it is suggested that the UV data were subject to interference by another absorbing species in these cases. Therefore, for $p$-xylene the simulated $\mathrm{O}_{3}$ was compared to the FTIR measurements.

Typical uncertainties $(2 \sigma)$ were $\pm 10 \%$ for $\mathrm{NO}_{2}$, aromatics, $\mathrm{HCHO}$ and $\pm 5 \%$ for $\mathrm{O}_{3}$ and $\mathrm{NO}$ (Volkamer et al., 2002; Zádor et al., 2004).

To measure concentrations of substituted phenol compounds samples of chamber air were taken using a stripping technique with a buffer solution of $\mathrm{H}_{2} \mathrm{O}$ at $\mathrm{pH}=7$; these samples were then analysed by HPLC-UV/FLD.

Measurements of $\mathrm{HO}_{\mathrm{x}}$ radical concentrations can be made in chamber $\mathrm{A}$; air is sampled by gas expansion and $\mathrm{OH}$ concentrations are measured by LIF. $\mathrm{HO}_{2}$ concentrations can be measured by using $\mathrm{NO}$ to convert $\mathrm{HO}_{2}$ to $\mathrm{OH}$ before the LIF measurement. This technique was employed during some of the aromatic hydrocarbon experiments described here, and the measurements are discussed in detail elsewhere (Bloss et al., 2003). These measurements show good agreement between $[\mathrm{OH}]$ calculated from the rate of decay of the aromatic and that measured by LIF, confirming the validity of the FAGE calibration within the quoted $1 \sigma$ measurement uncertainty of $26 \%$.

\section{Results and discussion}

\subsection{Chamber dependent reactions}

The effects of the chamber dependent reactions listed in Table 2 were investigated with reference to two ethene photosmog experiments as discussed in Sect. 2.4 above. Initially each experiment was simulated using the chemical mechanism from MCMv3 and a base case auxiliary mechanism with all parameters set to nominal values. As shown in Fig. 1, the observed ethene concentrations were well simulated but the maximum ozone concentration reached was over-predicted by the models, by $24 \%$ for the low $\mathrm{NO}_{\mathrm{x}}$ case and $23 \%$ for the high $\mathrm{NO}_{\mathrm{x}}$ case. The sensitivity of the $\mathrm{O}_{3}$ production to each parameter in the auxiliary mechanism was assessed by changing each parameter in turn to its upper and lower limit, keeping all other parameters at their nominal values. The resultant percentage change in maximum $\mathrm{O}_{3}$ was evaluated relative to the base case, and Fig. 2 shows the results for the two sets of experimental conditions, one in the $\mathrm{NO}_{\mathrm{x}}$ limited and one in the VOC limited regime. For the high $\mathrm{NO}_{\mathrm{x}}$, VOC limited experiment the initial HONO concentration used has largest effect on maximum $\mathrm{O}_{3}$ concentration reached, decreasing the initial $\mathrm{HONO}$ concentration to zero results in a $4 \%$ decrease in maximum $\mathrm{O}_{3}$ concentration. Decreasing the rate of $\mathrm{NO}_{2}$ conversion to $\mathrm{HONO}$ and $\mathrm{HNO}_{3}$ also decreases the $\mathrm{O}_{3}$ production. HONO photolysis is an important radical source and decreasing the radical production results in shorter chain lengths and reduced $\mathrm{O}_{3}$ formation. The situation is markedly different in $\mathrm{NO}_{\mathrm{x}}$ limited conditions where the light dependent wall source of $\mathrm{NO}_{2}$ has the largest effect on maximum $\mathrm{O}_{3}$ concentration; reducing this rate to its lower limit leads to a $7.4 \%$ decrease in $\mathrm{O}_{3}$. In these conditions increasing the rate of $\mathrm{NO}_{2}$ conversion to $\mathrm{HONO}$ and $\mathrm{HNO}_{3}$ decreases the $\mathrm{O}_{3}$ production as more $\mathrm{NO}_{2}$ is lost to wall-bound $\mathrm{HNO}_{3}$. As the system is $\mathrm{NO}_{\mathrm{x}}$ limited reducing the amount of $\mathrm{NO}_{\mathrm{x}}$ available decreases the conversion of peroxy radicals to alkoxy radicals by reaction with $\mathrm{NO}$; chain length and $\mathrm{O}_{3}$ formation are consequently reduced.

To assess the maximum impact of the chamber dependent reactions on the simulations a worst-case scenario was constructed for each ethene experiment by setting the important parameters to maximise $\mathrm{O}_{3}$ production and increase the overprediction observed with the base case mechanism. A single tuned mechanism was also constructed from the information obtained from both experiments to generate the best overall simulation of the datasets. The initial HONO concentration was chosen separately for each experiment to best reproduce the early time dependence of the observed ethene, $\mathrm{O}_{3}, \mathrm{NO}$ and $\mathrm{NO}_{2}$ concentrations, with a value of $0.1 \mathrm{ppb}$ being used for the low $\mathrm{NO}_{\mathrm{x}}$ experiment and $1.5 \mathrm{ppb}$ for the high $\mathrm{NO}_{\mathrm{x}}$ 

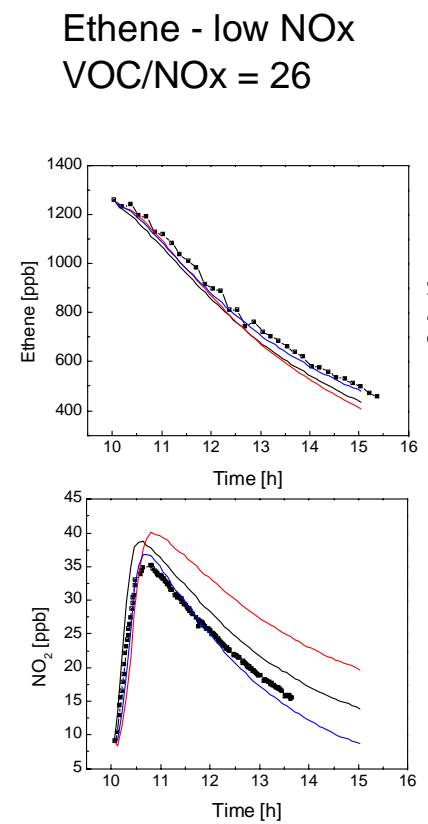
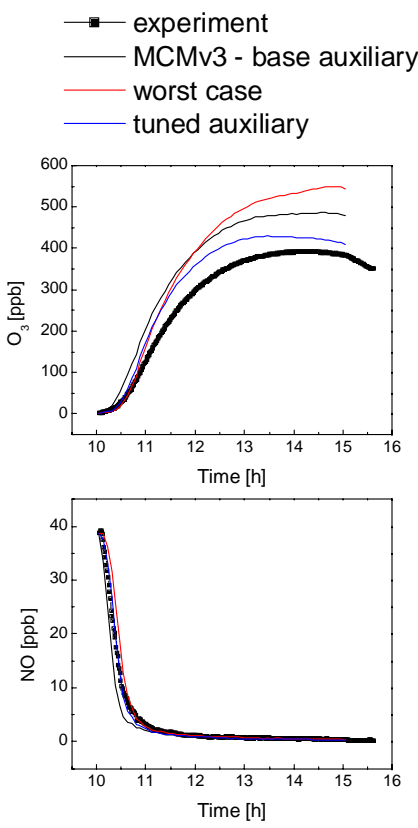
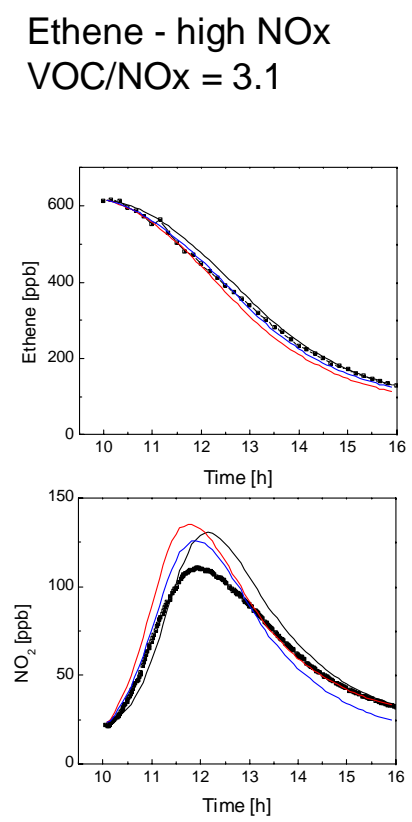
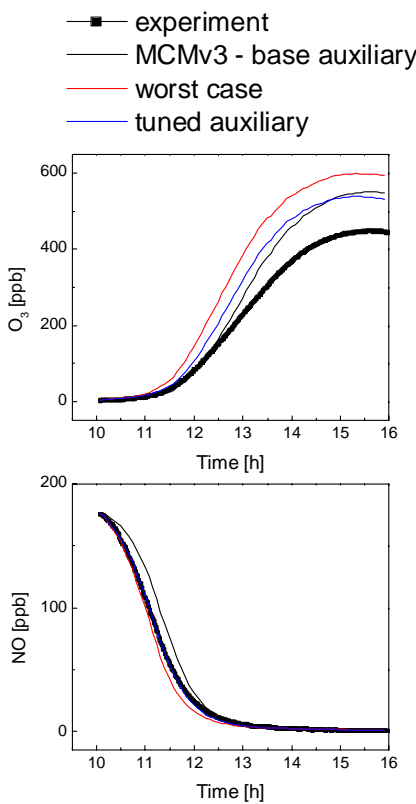

Fig. 1. Simulations of the ethene photosmog experiments with base case, worst case and tuned auxilary mechanism.

\section{High $\mathrm{NO}_{\mathrm{x}}-01 / 10 / 01$}

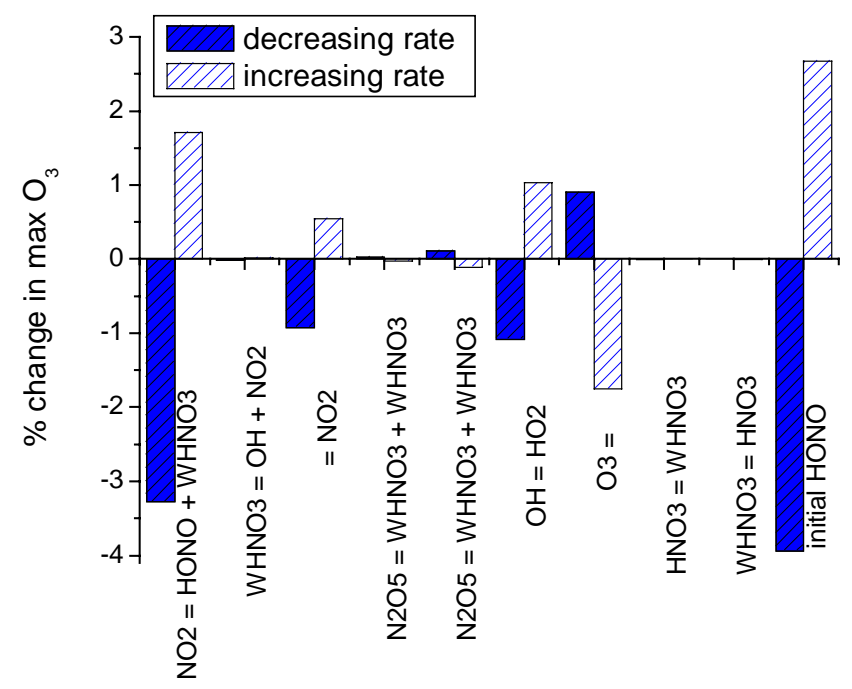

\section{Low $\mathrm{NO}_{\mathrm{x}}-11 / 09 / 01$}

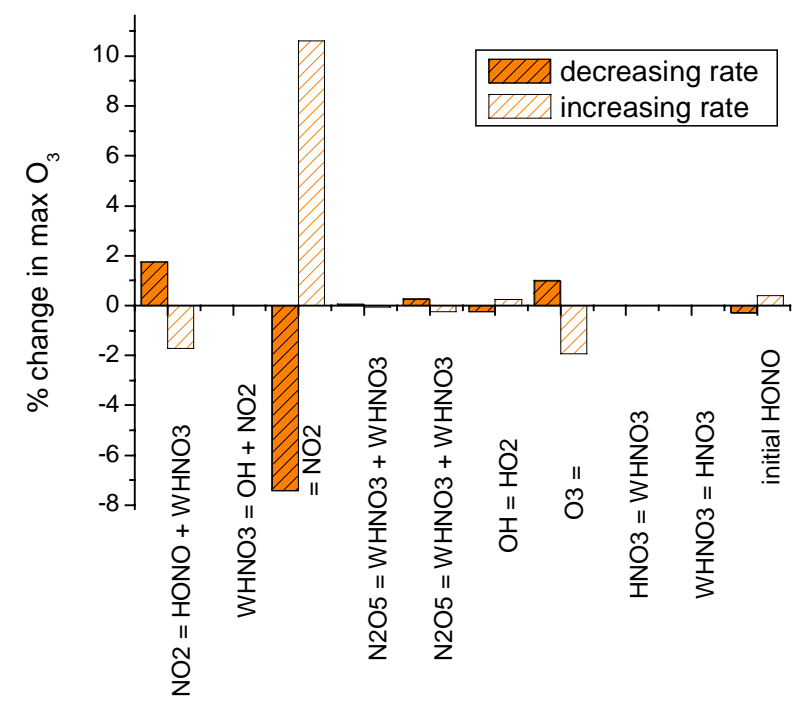

Fig. 2. $\mathrm{O}_{3}$ sensitivity to auxiliary mechanism for two ethene photosmog experiments.

experiment. The parameters used are summarised in Table 4; all reactions that produced less than $1 \%$ change in maximum $\mathrm{O}_{3}$ concentration in the sensitivity analysis were removed from the mechanism to minimise unnecessary complexity. The model-measurement comparison for the ethene experiments is shown in Fig. 1. The tuned auxiliary mechanism clearly results in better simulation of the experimental data but it was not possible to eliminate the $\mathrm{O}_{3}$ over-prediction.
The contribution of the chamber related processes to the overall radical and $\mathrm{NO}_{\mathrm{x}}$ budgets has been calculated for all three scenarios for both ethene experiments and the results, integrated over each five hour experiment, are summarised in Table 5. The radical source arising from the auxiliary mechanism by photolysis of the HONO produced is compared to the total radical production in the mechanisms expressed in terms of new $\mathrm{OH}$ equivalents (Wagner et al., 2003). The sources and sinks of $\mathrm{NO}_{2}$ within the auxiliary mechanism are 
Table 4. Parameters for three auxiliary mechanisms used to assess impact of chamber related processes on ethene experiments.

\begin{tabular}{l|l|l|l}
\hline \multicolumn{1}{c|}{ Process } & $\begin{array}{l}\text { Worst case } \\
\left(\text { low } \mathrm{NO}_{\mathrm{x}}\right)\end{array}$ & $\begin{array}{l}\text { Worst case } \\
\left(\text { high } \mathrm{NO}_{\mathrm{x}}\right)\end{array}$ & Tuned (both expts) \\
\hline \hline $\mathrm{NO}_{2}=\mathrm{HONO}$ & $0.7 \mathrm{e}-5 \mathrm{~s}^{-1}$ & $1.6 \mathrm{e}-5 \mathrm{~s}^{-1}$ & $0.7 \mathrm{e}-5 \mathrm{~s}^{-1}$ \\
\hline $\mathrm{NO}_{2}=\mathrm{wHNO}_{3}$ & $0.7 \mathrm{e}-5 \mathrm{~s}^{-1}$ & $1.6 \mathrm{e}-5 \mathrm{~s}^{-1}$ & $1.6 \mathrm{e}-5 \mathrm{~s}^{-1}$ \\
\hline $\mathrm{hv}=\mathrm{NO}_{2}$ & $0.2 * \mathrm{~J}_{\mathrm{NO} 2}$ & $0.2 * \mathrm{~J}_{\mathrm{NO} 2}$ & - \\
\hline $\mathrm{OH}=\mathrm{HO}_{2}$ & - & $12.5 \mathrm{~s}^{-1}$ & - \\
\hline $\mathrm{O}_{3}=\mathrm{wO}_{3}$ & $1.5 \mathrm{e}-6 \mathrm{~s}^{-1}$ & $1.5 \mathrm{e}-6 \mathrm{~s}^{-1}$ & $3 \mathrm{e}-6 \mathrm{~s}^{-1}$ \\
\hline Initial $\mathrm{HONO}$ & $0 \mathrm{ppb}$ & $1.5 \mathrm{ppb}$ & $\mathrm{NO}_{\mathrm{x}}$ dependent \\
\hline
\end{tabular}

considered and expressed as a net source, a negative value representing a net sink, and this is compared to the initial $\mathrm{NO}_{\mathrm{x}}$ concentration for the experiment or the total $\mathrm{NO}_{\mathrm{x}}$ sink in the system. In the low $\mathrm{NO}_{\mathrm{x}}$ experiment the auxiliary radical source is low compared to the total radical source but the chamber related reactions have a significant effect on the $\mathrm{NO}_{\mathrm{x}}$ budget. In the high $\mathrm{NO}_{\mathrm{x}}$ experiment the chamber related $\mathrm{NO}_{\mathrm{x}}$ sources and sinks are less important than in the low $\mathrm{NO}_{\mathrm{x}}$ case, but the auxiliary radical source makes a larger contribution to overall radical production.

The same base case, worst case and tuned auxiliary mechanisms applied to the ethene experiments were also used in models with MCMv3 to simulate two toluene experiments, one low $\mathrm{NO}_{\mathrm{x}}\left(12\right.$ September 2001) and one high $\mathrm{NO}_{\mathrm{x}}(25$ September 2001). The model-measurement comparison for the toluene experiments is shown in Fig. 3. It is clearly demonstrated that, although the simulations are sensitive to the parameters used in the auxiliary mechanism, these reactions cannot account for the observed model-measurement discrepancies. The radical source arising from the auxiliary mechanism can be compared to the amount of $\mathrm{OH}$ production identified as 'missing' from the MCMv3 chemistry (see below in Sect. 4.2.2 and Table 6). For the high $\mathrm{NO}_{\mathrm{x}}$ case the worst case auxiliary mechanism produces $44.6 \mathrm{ppb} \mathrm{OH}$ over the whole course of the simulation, $14 \%$ of 'missing $\mathrm{OH}$ ', the tuned auxiliary mechanism gives only $18.4 \mathrm{ppb}(6 \%$ of 'missing $\mathrm{OH}^{\prime}$ '). In the low $\mathrm{NO}_{\mathrm{x}}$ experiment radical production is much lower, the $\mathrm{OH}$ from the auxiliary mechanism is at most $3.0 \mathrm{ppb}$, or $2 \%$ of the 'missing $\mathrm{OH}^{\prime}$ for this experiment.

Chamber related processes introduce additional uncertainties into model simulation results, but particularly for the aromatic compounds further significant differences exist between modelled and measured concentrations, and the chamber datasets can be used to explore shortcomings in the understanding of the gas phase chemical mechanisms.

Similar conclusions were drawn by Zádor et al. (2004) applying uncertainty analysis to a comparison of MCMv3 simulations with data from the same two ethene experiments considered in this work. They included the reaction
Table 5. Ethene photosmog experiments: contribution of chamber related reactions to overall radical and $\mathrm{NO}_{\mathrm{x}}$ budgets. $\Sigma \mathrm{OH}_{\text {new }}$ refers to the total new $\mathrm{OH}$ produced in the photochemical system (Wagner et al., 2003).

\begin{tabular}{|c|c|c|c|c|c|c|}
\hline & \multicolumn{3}{|c|}{ Low $\mathrm{NO}_{\mathrm{x}}(11 / 09 / 01)$} & \multicolumn{3}{|c|}{ High $\mathrm{NO}_{\mathrm{x}}(01 / 10 / 01)$} \\
\hline & $\begin{array}{l}\text { Base } \\
\text { case }\end{array}$ & $\begin{array}{l}\text { Worst } \\
\text { case }\end{array}$ & Tuned & $\begin{array}{l}\text { Base } \\
\text { case }\end{array}$ & $\begin{array}{l}\text { Worst } \\
\text { case }\end{array}$ & Tuned \\
\hline $\begin{array}{l}\text { Auxiliary radical } \\
\text { source }(\mathrm{ppb})\end{array}$ & 5.2 & 3.3 & 5.6 & 15.1 & 22.6 & 10.1 \\
\hline $\begin{array}{l}\text { Radical source } \\
\left(\% \text { of } \Sigma \mathrm{OH}_{\text {new }}\right)\end{array}$ & 2 & 1 & 2 & 11 & 13 & 7 \\
\hline $\begin{array}{l}\text { Auxiliary net } \mathrm{NO}_{2} \\
\text { source (ppb) }\end{array}$ & 8.6 & 23.8 & -6.0 & -2.5 & 4.5 & -10.3 \\
\hline$\%$ of initial $\mathrm{NO}_{\mathrm{x}}$ & 18 & 50 & & & 2 & \\
\hline$\%$ of $\mathrm{NO}_{\mathrm{x}} \operatorname{sink}$ & & & 25 & 2 & & 9 \\
\hline
\end{tabular}

$\mathrm{NO}_{2}=\mathrm{HONO}$ as a chamber radical source in the models and found this reaction to have no significant effect on the final $\mathrm{O}_{3}$ concentration in the low $\mathrm{NO}_{\mathrm{x}}$ case. For the high $\mathrm{NO}_{\mathrm{x}}$ experiment the chamber radical source was seen to have a non-linear effect on $\mathrm{O}_{3}$ concentration, but this effect was relatively minor and the uncertainty arising from this parameter alone could not account for the $\mathrm{O}_{3}$ over-prediction observed.

In all the simulations of the aromatic experiments described below the tuned auxiliary mechanism obtained by consideration of the two ethene experiments was used. In order to simulate the concentration-time profile of $\mathrm{HNO}_{3}$, an important compound for the $\mathrm{NO}_{\mathrm{y}}$ budget, its wall loss process was also included, and the nominal rate from EUPHORE characterisation experiments was assumed. The inclusion of this process and the value of the rate parameter do not significantly affect the simulated concentrations of any other species.

The initial HONO concentrations used in the models are listed in Table 1. In two experiments HONO was introduced into the chamber in relatively high concentration ( 9 and 18 July 2002) and the values used are those measured before the chamber was opened. In the replacement $\mathrm{NO}_{\mathrm{x}}$ experiments (14 and 17 September 2001) a mixture of HONO, NO and $\mathrm{NO}_{2}$ was introduced into the chamber at a variable but known rate throughout the experiment and the values used for initial HONO were calculated from the amount added before chamber opening in each experiment. In the other experiments the initial HONO concentration is not known and the concentrations used in the ethene simulations discussed above were used as an approximation, i.e. in low $\mathrm{NO}_{\mathrm{x}}$ conditions $0.1 \mathrm{ppb}$ was assumed and in high $\mathrm{NO}_{\mathrm{x}}$ conditions $1.5 \mathrm{ppb}$ was assumed. This is an estimation used in the absence of more reliable methods and the facility to measure low concentrations 

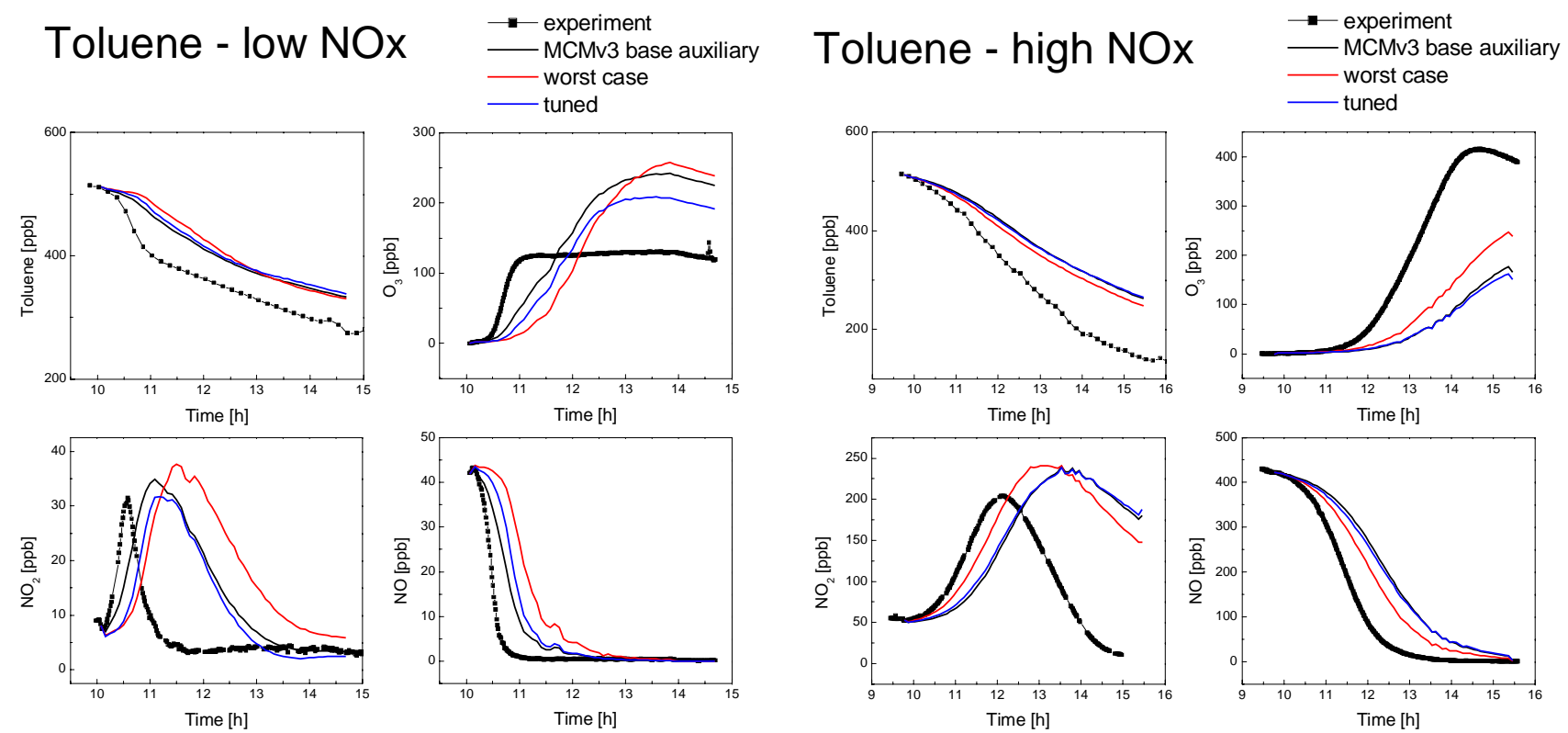

Fig. 3. Simulations of toluene photosmog experiments with base case, worst case and tuned auxiliary mechanism as determined from analysis of the ethene experiments.

of HONO in the chamber would be a valuable addition to the instrumentation available at EUPHORE. However, as discussed above, the contribution of the chamber HONO source to the overall radical production in the aromatic systems is small compared to the gas phase chemical sources and cannot account for the discrepancies observed between the modelled and measured concentrations.

\subsection{Evaluation of aromatic mechanisms}

\subsubsection{Update of MCMv3 to MCMv3.1}

The twelve aromatic photosmog experiments carried out during the EXACT campaigns were simulated as described above by models using both MCMv3 and MCMv3.1 mechanisms. The updates to MCMv3 resulting in MCMv3.1 have been made on the basis of information from current literature and conference proceedings, and the main updates are as follows:

- Photolysis rates of unsaturated $\gamma$-dicarbonyls have been adjusted according to Thuener et al. (2003) for butenedial and 4-oxo-2-pentenal, and Graedler and Barnes (1997) for 3-hexene-2,5-dione. The photolysis rates of the epoxydicarbonylene products have also been increased as they were originally estimated by analogy with the unsaturated $\gamma$-dicarbonyls.

- The breakdown of the carbon skeleton for $2(5 \mathrm{H})$ furanone has been updated and $\beta$-angelica lactone has been replaced by $\alpha$-angelica lactone to reduce the secondary glyoxal formation. These changes were prompted by findings of Volkamer et al. (2001) that secondary glyoxal formation in the toluene system is negligible.

- New phenol-type chemistry has been implemented reflecting the lower yield for the ring-opening channel reported by Olariu et al. (2002), and the need for reduced ozone formation found in a cresol photosmog experiment at EUPHORE.

- Branching ratios for the different oxidation routes of aromatics have been adjusted to reflect the reported yields of glyoxal and of phenol-type compounds at $\mathrm{NO}_{\mathrm{x}}$ levels appropriate to the atmosphere (Volkamer et al., 2001, 2002).

The process of mechanism development and further details of the differences between the two mechanism versions are described in detail in a companion paper (Bloss et al., 2005).

\subsubsection{First group of key species: parent aromatic, $\mathrm{O}_{3}, \mathrm{NO}_{2}$, NO}

The results of the simulations were compared to the measured concentrations of the key species. Figures 4-7 exemplify model-measurement comparisons for the first group of target species, the parent aromatic, $\mathrm{O}_{3}, \mathrm{NO}_{2}$ and NO.

The ability of the models to simulate observed ozone production and oxidative capacity can be evaluated by consideration of the observed and calculated maximum ozone concentrations and $\mathrm{NO}$ oxidation rates, and the amount of $\mathrm{OH}$ radical found to be missing from the chemical mechanism as discussed above. These measures of model performance 
Table 6. Measures of model performance concerning the ozone formation and oxidation capacity for MCMv3 and $\mathrm{MCMv} .1$. For $\mathrm{O}_{3}$ the peak values are taken irrespective of the time they occur, NO oxidation rate is a measure for the timing of the simulation (see text), and the numbers in bold for these measures are the percentage difference between simulated and observed value, relative to the observed value. For missing $\mathrm{OH}$, base value is the amount of new $\mathrm{OH}$ produced by the base mechanism over the course of the experiment, "missing" is the amount of extra $\mathrm{OH}$ needed to achieve agreement between modelled and observed aromatic decay, and the number in bold is the missing $\mathrm{OH}$ as a percentage of the total $\mathrm{OH}$, (base + missing).

\begin{tabular}{|c|c|c|c|c|c|c|c|c|c|c|c|c|}
\hline \multirow{3}{*}{ VOC } & \multirow{3}{*}{ date } & \multirow{3}{*}{$\begin{array}{l}\mathrm{VOC} / \\
\mathrm{NO}_{\mathbf{x}}\end{array}$} & \multicolumn{3}{|c|}{$\mathbf{O}_{3}[\mathrm{ppb}]$} & \multicolumn{3}{|c|}{ NO oxidation rate $[\mathrm{ppb} / \mathrm{min}]$} & \multicolumn{4}{|c|}{ Missing OH [ppb] } \\
\hline & & & \multirow{2}{*}{ Obs. } & \multirow{2}{*}{ MCM3 } & \multirow{2}{*}{ MCM3.1 } & \multirow{2}{*}{ Obs. } & \multirow{2}{*}{ MCM3 } & \multirow{2}{*}{ MCM3.1 } & \multicolumn{2}{|c|}{ MCM3 } & \multicolumn{2}{|c|}{ MCM3.1 } \\
\hline & & & & & & & & & base & missing & base & missing \\
\hline \multirow{2}{*}{ ethene } & 110901 & 26 & 391 & 429 (10) & & 2.79 & 3.28 (15) & & 226 & 0 & & \\
\hline & 011001 & 3.1 & 446 & $536(20)$ & & 2.23 & $2.74(\mathbf{2 3})$ & & 147 & 0 & & \\
\hline \multirow{2}{*}{ benzene } & 080702 & 42 & 187 & 272 (45) & $181(-3)$ & 2.49 & $2.48 \quad(-1)$ & $1.83(-27)$ & 84 & 338 (80) & 45 & $339(\mathbf{8 8})$ \\
\hline & 090702 & 5.6 & 231 & 349 (51) & $233(1)$ & 2.26 & 2.77 (23) & $1.96(-14)$ & 168 & $222(57)$ & 119 & $250(\mathbf{6 8})$ \\
\hline \multirow{5}{*}{ toluene } & 140901 & $\sim 60$ & 171 & $240 \quad(41)$ & $218 \quad(\mathbf{2 8})$ & & & & 82 & 277 (77) & 69 & $328(\mathbf{8 3})$ \\
\hline & 120901 & 10.2 & 131 & 204 (56) & 189 (44) & 3.07 & $0.57(\mathbf{- 8 2})$ & $1.89(\mathbf{- 3 8})$ & 59 & 129 (69) & 48 & $181(\mathbf{7 9})$ \\
\hline & 240901 & 10 & 149 & $230(54)$ & $218(\mathbf{4 6})$ & 4.40 & $0.60(-86)$ & $2.58(-41)$ & 63 & $150(71)$ & 52 & $183(78)$ \\
\hline & 270901 & 3.5 & 255 & 345 (35) & 346 (36) & 3.63 & $1.12(-69)$ & $2.22(-39)$ & 119 & 231 (66) & 107 & $255(70)$ \\
\hline & 250901 & 1.1 & 416 & $155(-63)$ & $185(-55)$ & 3.00 & $1.39(-\mathbf{5 4})$ & $1.92(-\mathbf{3 6})$ & 210 & $328(\mathbf{6 1})$ & 211 & $293(58)$ \\
\hline \multirow{2}{*}{$p$-xylene } & 030702 & 3.9 & 319 & $465 \quad(46)$ & $439 \quad$ (38) & 3.29 & 3.72 (13) & $4.38 \quad(33)$ & 161 & $198(\mathbf{5 5})$ & 152 & $318(68)$ \\
\hline & 180702 & 1.5 & 362 & 409 (13) & $389(7)$ & 5.00 & 5.03 & $4.47(-11)$ & 155 & 73 (32) & 128 & 99 (44) \\
\hline \multirow{3}{*}{$\begin{array}{l}1,3,5- \\
\text { TMB }\end{array}$} & 170901 & $\sim 30$ & 241 & 298 (24) & 334 (39) & & & & 219 & $146(40)$ & 198 & $119(\mathbf{3 8})$ \\
\hline & 210901 & 4.6 & 152 & 291 (91) & 294 (93) & 6.42 & $0.43(-93)$ & $2.84(\mathbf{- 5 6 )}$ & 169 & 4.5 (2.6) & 128 & $0.3(\mathbf{0 . 2})$ \\
\hline & 260901 & 1.0 & 396 & $507(\mathbf{2 8})$ & $525(\mathbf{3 3})$ & 9.69 & $2.48(-65)$ & $6.55(-32)$ & 325 & $58(\mathbf{1 5})$ & 277 & $50(15)$ \\
\hline
\end{tabular}

are summarised for each experiment in Table 6 for MCMv3 and MCMv3.1. The investigated aromatics form a series of compounds with increasing methyl substitution, and for each compound a range of $\mathrm{VOC} / \mathrm{NO}_{\mathrm{x}}$ ratios is covered by the experiments. The results for the ethene experiments are included to show the level of agreement reached for a system where the chemistry is well understood, though even in this case the results of the uncertainty analysis performed by Zádor et al. (2004) suggest some systematic over-prediction of $\mathrm{O}_{3}$ concentration.

In the experiments of 14 and 17 September 2001 the $\mathrm{NO}_{\mathrm{x}}$ concentration was kept at a constant low level $(\sim 5-7 \mathrm{ppb})$ by a feedback mechanism and therefore NO oxidation rate is not a useful measure for these experiments and is not included in the table. It should be noted that in the VOC limited experiments (25 September 2001 and 9 July 2002) the simulated ozone concentration does not reach a peak on the timescale of the experiment, therefore the values listed in the table are the ozone concentrations at the end of the experiments and may under-estimate the $\mathrm{O}_{3}$ peak value.

The two low $\mathrm{NO}_{\mathrm{x}}$ toluene experiments (12 and 24 September 2001) used similar initial conditions and the good agreement between measures of model performance for these two days shows that reproducible results are obtained from these chamber studies.

\section{Performance of MCMv3}

The simulations over-predict the peak $\mathrm{O}_{3}$ concentration, with the exception of the toluene high $\mathrm{NO}_{\mathrm{x}}(25$ September 2001) experiment where the simulated peak $\mathrm{O}_{3}$ is not reached. The peak $\mathrm{O}_{3}$ of the ethene experiments is over-predicted by $10 \%$ and $20 \%$ for the low and high $\mathrm{NO}_{\mathrm{x}}$ cases, respectively; the chemical mechanism for this simple alkene is well understood and this relatively small discrepancy between modelled and observed concentrations may be considered the best we could expect to achieve for the aromatic experiments. In fact only one of the aromatic simulations gives a discrepancy in this range, which is $13 \%$ for the $p$-xylene higher $\mathrm{NO}_{\mathrm{x}}$ experiment. Discrepancies as high as $91 \%$ are seen $(1,3,5-$ TMB low $\mathrm{NO}_{\mathrm{x}}$ ) with a more typical value being around $50 \%$. In general, for the "classical photosmog" experiments, the mechanism seems to perform better when simulating peak ozone in the higher $\mathrm{NO}_{\mathrm{x}}$ conditions. The peak $\mathrm{O}_{3}$ in the two experiments where $\mathrm{NO}_{\mathrm{x}}$ levels were maintained at a low and constant level is also simulated better than for the classical low $\mathrm{NO}_{\mathrm{x}}$ experiments. There is no clear trend in the ability of the model to simulate peak $\mathrm{O}_{3}$ with increasing substitution of the aromatic ring.

The NO oxidation rate is reasonably well simulated by MCMv3 for the two ethene experiments, over-predicting the observed rate by $15 \%$ and $23 \%$ for the low and high $\mathrm{NO}_{\mathrm{x}}$ cases, respectively, and, as for the peak $\mathrm{O}_{3}$, these values give some indication of the best level of agreement we may expect for the more complex aromatic systems. As shown in 

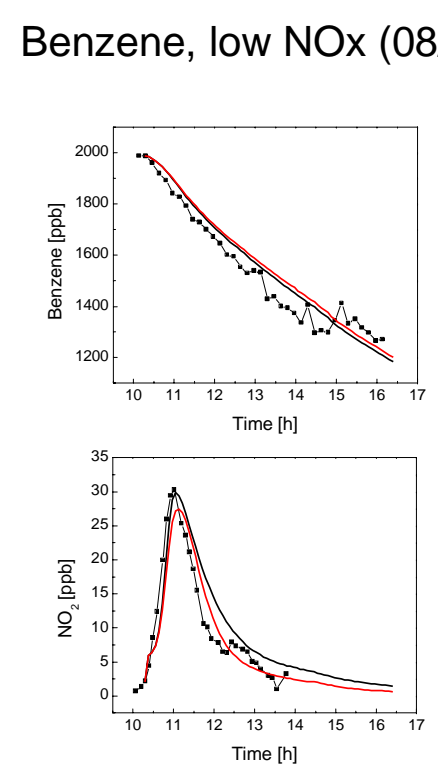
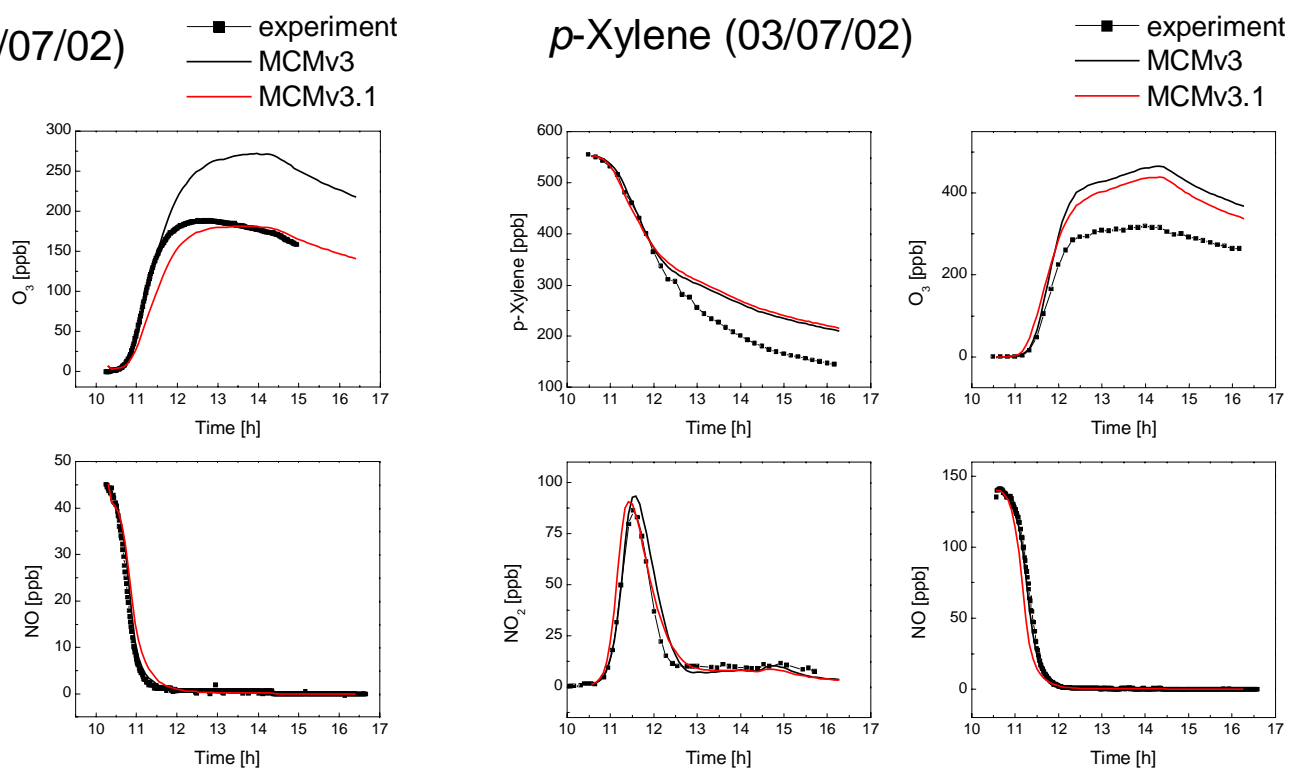

Fig. 4. Model-measurement comparison for benzene, $\mathrm{O}_{3}, \mathrm{NO}_{2}$ and NO in benzene photosmog experiment of 8 July 2002.
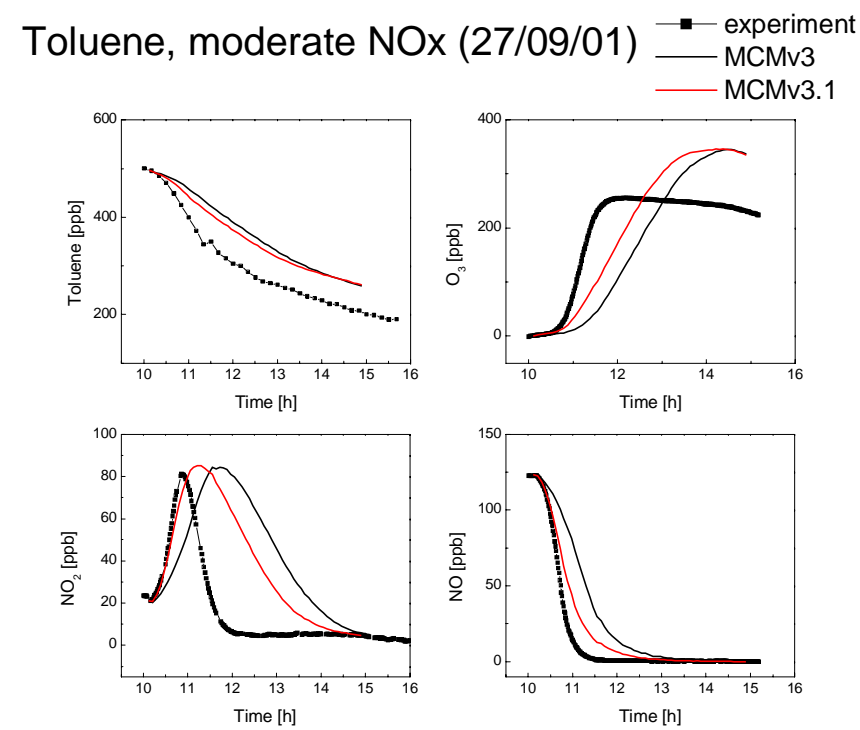

Fig. 5. Model-measurement comparison for toluene, $\mathrm{O}_{3}, \mathrm{NO}_{2}$ and NO in toluene photosmog experiment of 27 September 2001.

Table 6, MCMv3 achieves good agreement between modelled and measured NO oxidation rate for benzene and $p$ xylene, while for toluene and 1,3,5-TMB the model significantly under-predicts the observed value. This is also clear from Figs. 4-7 where the timing of the simulations appears in good agreement with measurements for benzene and $p$ xylene but simulations of the toluene and 1,3,5-TMB experiments show a delay relative to the measurements. For a given aromatic the modelled NO oxidation rate increases with in-
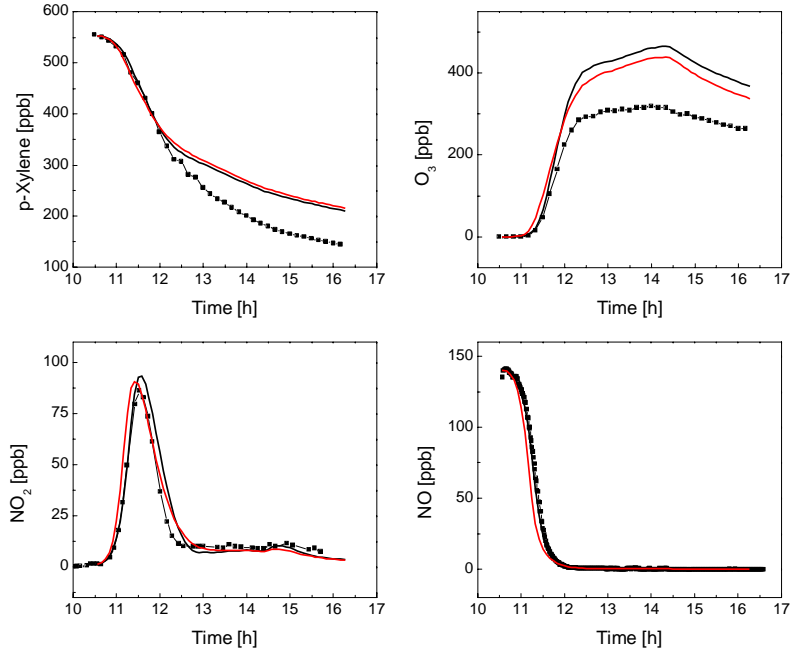

Fig. 6. Model-measurement comparison for $p$-xylene, $\mathrm{O}_{3}, \mathrm{NO}_{2}$ and NO in $p$-xylene photosmog experiment of 3 July 2002.
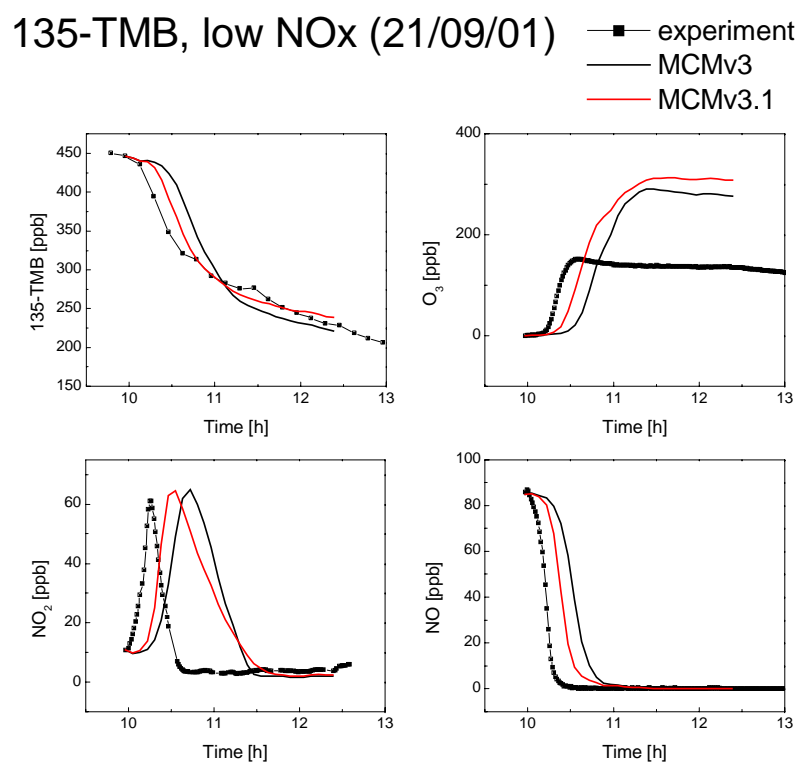

Fig. 7. Model-measurement comparison for 1,3,5trimethylbenzene, $\mathrm{O}_{3}, \mathrm{NO}_{2}$ and $\mathrm{NO}$ in 1,3,5-TMB photosmog experiment of 21 September 2001.

creasing initial $\mathrm{NO}_{\mathrm{x}}$, and in most cases this results in improved model-measurement agreement at higher initial $\mathrm{NO}_{\mathrm{x}}$ concentrations.

The measure of the $\mathrm{OH}$ source missing from the mechanism is taken to be the amount of $\mathrm{OH}$ which needs to be added to the system to achieve agreement between modelled and observed decay of the parent compound over the whole experiment, expressed as a percentage of the total $\mathrm{OH}$ source 
in that model. In the case of the ethene experiments, the MCMv3 simulation gives a good description of the ethene loss and no $\mathrm{OH}$ source is missing. However, for most of the aromatic experiments a significant $\mathrm{OH}$ addition is required, with a missing $\mathrm{OH}$ of up to $80 \%$ for benzene. In general, the models seem to have less missing $\mathrm{OH}$ in the higher initial $\mathrm{NO}_{\mathrm{x}}$ conditions, in line with the improved simulation of the timing parameter (NO oxidation rate), which is related to the oxidative capacity of the system. The exception is the 1,3,5-TMB experiments where missing $\mathrm{OH}$ is relatively low for all experiments. There is also a trend to lower missing $\mathrm{OH}$ with increasing methyl substitution, and hence with increasing reactivity of the aromatic. For benzene the model-measurement comparison (Fig. 4) shows the parent compound decay to be reasonably well simulated, but as the rate of reaction of $\mathrm{OH}$ with benzene is slow a large additional concentration of $\mathrm{OH}$ is needed to correct for the small under-prediction of the loss rate. Much of the benzene decay is accounted for by chamber air dilution, and the 'missing' $\mathrm{OH}$ measure of model performance is more appropriate for the higher reactivity systems where most of the aromatic decay is a result of $\mathrm{OH}$ reaction. It should also be noted that for each experiment there is not a fixed amount of $\mathrm{OH}$ production needed to produce the observed decay in aromatic, the amount depending on the lifetime of $\mathrm{OH}$, and hence on the concentrations of products which depend on the details of the chemical mechanism.

\section{Performance of MCMv3.1 compared to MCMv3}

(1) Benzene. The $\mathrm{O}_{3}$ peak in the benzene system is greatly reduced in the MCMv3.1 compared to MCMv3, and is in good agreement with the measurement, as shown in Fig. 4. This substantial improvement is mainly as a result of an increased phenol channel yield implemented in MCMv3.1 and an increased ring-retaining product yield in that channel. Sensitivity studies have shown the ring-opening routes to be generally the most efficient at generating ozone (Jenkin et al., 2000; Wagner et al., 2003). This is partly because the products, such as $\alpha$-dicarbonyls and conjugated $\gamma$-dicarbonyls, rapidly photolyse to generate radicals and hence increase reactivity in the system and promote ozone formation from VOC oxidation. Also these routes proceed via the formation of peroxy radicals and involve two NO-to- $\mathrm{NO}_{2}$ conversion steps in the initial oxidation step. In contrast the initial oxidation of benzene to phenol involves only one NO-to- $\mathrm{NO}_{2}$ conversion step, the phenol product is not a radical source, and in MCMv3.1 the subsequent chemistry results mainly in the formation of further substituted aromatics, including nitro-phenol and nitro-catechol which act as a sink of $\mathrm{NO}_{2}$ and reduce the $\mathrm{NO}_{\mathrm{x}}$ available for ozone formation. However, this increase in ring-retaining yield and consequent decrease in radical production leads to an increase in missing $\mathrm{OH}$, and a decrease in the NO oxidation rate which was well simulated by MCMv3 for the benzene experiments. This is indicative of a general problem with the mechanisms, overprediction of the ozone concentration but under-prediction of the reactivity of the system. Reducing the ozone production by reducing the peroxy radical concentrations and hence the amount of $\mathrm{NO}$ to $\mathrm{NO}_{2}$ conversion also reduces the $\mathrm{OH}$ production and the oxidative capacity of the system.

(2) 1,3,5-trimethylbenzene. At the other end of the aromatic series, for 1,3,5-trimethylbenzene simulated ozone and NO oxidation rate both increase in MCMv3.1 relative to MCMv3, i.e. the opposite effects to those seen for benzene. An example is shown in Fig. 7. There is no new information on the substituted phenol yield for this compound so it remains unchanged from MCMv3, and as the aromatic ring is already substituted in the ortho and para positions relative to the phenol group the chemistry cannot be updated in an analogous way to the other phenols and also remains unchanged. The increased NO oxidation rate and ozone production is a result of the increased photolysis rates of the unsaturated dicarbonyl compounds producing more radicals in the early stages of the experiment.

(3) Toluene. The bulk of the development work in the project has focused on toluene and the model-measurement agreement in terms of both ozone concentration and NO oxidation is improved in MCMv3.1. An example is shown in Fig. 5. This mechanism has an increased branching ratio for ring opening in toluene oxidation, and a slightly decreased cresol yield. These changes, along with the increased photolysis rates of the unsaturated dicarbonyl compounds, tend to increase radical production, particularly early in the experiment, and increase $\mathrm{O}_{3}$ generation. However, changes to the substituted phenol (cresol) chemistry, analogous to those discussed above for the benzene system, decrease $\mathrm{O}_{3}$ formation and reduce radical production in the middle of the experiment. The changes balance out in such a way that some decrease in $\mathrm{O}_{3}$ formation is achieved while increasing the radical production in the early stages of the experiment, which are particularly significant in determining the $\mathrm{NO}$ oxidation rate. However, the missing $\mathrm{OH}$ is calculated over the whole course of the experiment, and in general is higher for the MCMv3.1 simulations indicating an overall reduction in oxidative capacity for this mechanism consistent with the reduced ozone formation potential. Note that for the high $\mathrm{NO}_{\mathrm{x}}$ experiment (25 September 2001) the simulated $\mathrm{O}_{3}$ value is higher for MCMv3.1 than MCMv3, but as discussed above, these simulations do not reach an $\mathrm{O}_{3}$ peak in the timeframe of the experiments. The higher radical production in the early stages of the MCMv3.1 simulation results in a faster rise in $\mathrm{O}_{3}$ and a higher $\mathrm{O}_{3}$ concentration at the end of the experiment in better agreement with the measurement, but still much lower than the observed peak. There is also a slight decrease in missing $\mathrm{OH}$ for this experiment as the simulation deals more with the early stages of toluene oxidation in which radical production is increased in MCMv3.1 compared to MCMv3. 
Table 7. Measures of model performance of MCMv3 and MCMv3.1 concerning some key species relating to the $\mathrm{NO}_{\mathrm{y}}$ budget, radical sources and product branching ratios. For all species the peak values (in ppb) are taken irrespective of the time they occur, and the figures in bold are the percentage difference between simulated and observed peak value, relative to the observed value.

\begin{tabular}{|c|c|c|c|c|c|}
\hline & & benzene & toluene & p-xylene & 135-TMB \\
\hline & & 080702 & 270901 & 030702 & 260901 \\
\hline \multirow{3}{*}{ PAN } & Obs. & \multirow{3}{*}{ not formed } & 24.4 & 30.5 & 125 \\
\hline & MCM3 & & 31.2 (28) & 59.2 (94) & $156(\mathbf{2 5})$ \\
\hline & MCM3.1 & & $21.5(-\mathbf{1 2})$ & 45.7 (50) & $124(-1)$ \\
\hline \multirow{3}{*}{$\mathrm{HNO}_{3}$} & Obs. & 16.2 & 35.9 & 18.7 & 30.0 \\
\hline & MCM3 & $8.7 \quad(-46)$ & $25.6(-29)$ & $18.8(\mathbf{1})$ & 35.0 (17) \\
\hline & MCM3.1 & $10.5(-35)$ & $29.2(-19)$ & $21.8(\mathbf{1 7})$ & $31.6(\mathbf{5})$ \\
\hline \multirow{3}{*}{ НСНО } & Obs. & 13.1 & 32.9 & 59.3 & 83.7 \\
\hline & MCM3 & $6.3(-52)$ & $16.8(-49)$ & $48.2(-19)$ & $56.1(-33)$ \\
\hline & MCM3.1 & $4.9 \quad(-\mathbf{6 2})$ & $22.4(-32)$ & $42.2(-29)$ & $50.1(-\mathbf{4 0})$ \\
\hline \multirow{3}{*}{ glyoxal } & Obs. & 22.4 & 34.4 & 43.5 & \multirow{3}{*}{ not formed } \\
\hline & MCM3 & 51.4 (130) & 38.2 (11) & $33.2(-24)$ & \\
\hline & MCM3.1 & $24.3(8)$ & $32.1(-7)$ & $41.9(-4)$ & \\
\hline \multirow{3}{*}{ methylglyoxal } & Obs. & \multirow{3}{*}{ not formed } & 20.2 & 32.6 & 138 \\
\hline & MCM3 & & $19.9(-2)$ & $78.6(\mathbf{1 4 1})$ & $162(17)$ \\
\hline & MCM3.1 & & $15.3(-25)$ & $48.2(\mathbf{4 8})$ & $101(-27)$ \\
\hline \multirow{3}{*}{$\begin{array}{c}\text { phenol/ } \\
\text { methylphenol }\end{array}$} & Obs. & 31.7 & 7.6 & 2.9 & \multirow{3}{*}{$\begin{array}{r}\text { no data } \\
\text { available }\end{array}$} \\
\hline & MCM3 & $10.6(-67)$ & 7.8 (2) & 7.8 (169) & \\
\hline & MCM3.1 & $26.2(-17)$ & $5.6(-26)$ & $5.5(\mathbf{8 8})$ & \\
\hline
\end{tabular}

(4) $p$-xylene. The changes to the $p$-xylene mechanism are very similar to those in toluene, and the simulated $\mathrm{O}_{3}$ peak is again lower for both experiments using the MCMv3.1 mechanism, while the missing $\mathrm{OH}$ increases as the overall oxidative capacity is decreased. An example is shown in Fig. 6. For the lower $\mathrm{NO}_{\mathrm{x}}$ experiment ( 3 July 2002) the NO oxidation rate is increased as for toluene, but unlike the toluene experiments where the NO oxidation rate is under-predicted, for this experiment MCMv3 slightly over-predicts the NO oxidation rate and the model-measurement discrepancy is therefore larger for $\mathrm{MCMv} 3.1$. In the higher $\mathrm{NO}_{\mathrm{x}} p$-xylene experiment (18 July 2002) the MCMv3.1 simulated NO oxidation rate is lower than MCMv3 and slightly under-predicts the observed value, though it remains in reasonable agreement with it.
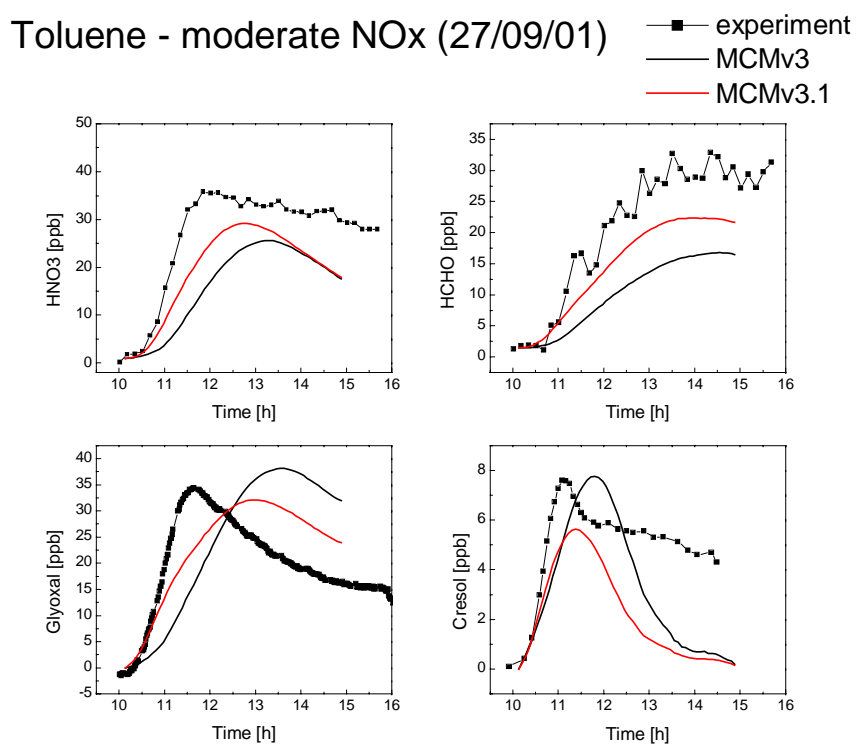

Fig. 8. Model-measurement comparison for $\mathrm{HNO}_{3}, \mathrm{HCHO}$, glyoxal and cresol in toluene photosmog experiment of 27 September 2001.

4.2.3 Second group of key species: glyoxal, methylglyoxal, phenol, $\mathrm{HCHO}, \mathrm{HNO}_{3}, \mathrm{PAN}$

The second group of key species are those that deliver important information on the $\mathrm{NO}_{\mathrm{y}}$ budget, the $\mathrm{HO}_{\mathrm{x}}$ production or the branching ratios for major reaction routes, and example model-measurement comparisons for some of these in a toluene experiment are shown in Fig. 8. The performance of MCMv3 and MCMv3.1 in simulating the concentrations of glyoxal, methylglyoxal, phenol, $\mathrm{HCHO}, \mathrm{HNO}_{3}$ and PAN in the aromatic experiments is summarised in terms of maximum observed and simulated concentrations in Table 7. Only one experiment for each aromatic is listed to illustrate the general performance of the mechanisms; a full table is available in the supplementary information.

(1) Glyoxal and methylglyoxal. These $\alpha$-dicarbonyls are primary products of the aromatic ring-opening routes, and have been identified as important radical sources. In the latest version of the mechanism, MCMv3.1, primary glyoxal yields based on the latest literature data (Volkamer et al., 2001) have been implemented and secondary production from the degradation of furanones, unsaturated $\gamma$ dicarbonyls and phenols has been reduced in line with the negligible secondary glyoxal yields observed experimentally. The simulated peak glyoxal concentration is in good agreement with the measurements. Primary methylglyoxal yields in MCMv3.1 have also been adjusted to maintain the ratio of glyoxal to methylglyoxal yield observed by (Smith et al., 1998, 1999), and the secondary yield has been reduced as for glyoxal. Model performance for methylglyoxal is not as good as for glyoxal but the simulated and observed peak concentrations agree to within $50 \%$. 
(2) Substituted phenols. The formation of substituted phenols is an important oxidation pathway of aromatics and, as discussed in Sect. 4.2.2, the yields and subsequent chemistry of these products have been updated in MCMv3.1. This has an impact on the ozone forming potential and general reactivity of the systems. In particular a large change in phenol yield was implemented for benzene and the MCMv3.1 simulated peak phenol concentration is in reasonable agreement with the measurement. The observed 2,5-dimethylphenol yield in the $p$-xylene experiment is very low and the models significantly over-predict the peak concentration. The overprediction is smaller for MCMv3.1 as a lower yield is implemented in this mechanism. For toluene the concentrationtime profiles for cresol (methylphenol) are shown in Fig. 8, and while the simulated peak concentrations are in reasonable agreement with the measured peak there are clear discrepancies in the time dependence. The delayed modelled peak is common to all products and is a consequence of the under-estimate of reactivity. Also the modelled loss of the cresol product in the latter stages of the experiment is too fast; this will tend to decrease the modelled peak concentration and contribute to the small under-prediction of the peak by MCMv3.1. This rapid loss process is connected to the $\mathrm{NO}_{y}$ budget as reaction with $\mathrm{NO}_{3}$ is a significant removal reaction for cresol. The cresol concentration can be used as a tracer for $\mathrm{NO}_{3}$ and the over-prediction of its loss rate is indicative of an over-prediction in $\mathrm{NO}_{3}$. Use of these data for mechanism development is discussed in the companion paper (Bloss et al., 2005).

(3) Formaldehyde. Formed as a second and subsequent generation product in many areas of the aromatic mechanisms, formaldehyde has been found to be a significant radical source in these systems. Its peak concentration is underpredicted to some degree by both mechanisms and for all the target aromatics. For the methyl-substituted aromatics the model-measurement discrepancy for MCMv3.1 is at worst $40 \%$, but for benzene a more significant under-prediction, $62 \%$ with MCMv3.1, is observed. The main sources of formaldehyde in this mechanism are the photolysis of glyoxal and the degradation of 5H-furan-2-one. The observed concentration-time profile suggests that additional formaldehyde production is required particularly in the later stages of the experiment.

(4) PAN and $\mathrm{HNO}_{3}$. The concentrations of PAN and $\mathrm{HNO}_{3}$ give information on the $\mathrm{NO}_{\mathrm{y}}$ budget in the system. $\mathrm{HNO}_{3}$ is mostly formed by the chain termination reaction of $\mathrm{OH}$ with $\mathrm{NO}_{2}$ and also in the reaction of $\mathrm{NO}_{3}$ with aldehydes and phenol compounds. The peak concentration is simulated reasonably well by MCMv3.1. However, as shown in Fig. 8 for toluene, the concentration-time profile is not well simulated, the modelled concentration decays faster than observed. Additional uncertainty is introduced into the model for this polar compound by the need to include a wall loss term. The value used for this parameter was taken from a single experiment at EUPHORE and may depend on the con- dition of the chamber walls and be too high for these experiments. Also, as $\mathrm{HNO}_{3}$ loss in the chamber has been seen to deviate from a first order decay it may be more appropriate to use both wall adsorption and deposition processes for $\mathrm{HNO}_{3}$. Given the apparent over-estimate of $\mathrm{HNO}_{3}$ losses the simulated peak concentrations should be considered as a lower limit of $\mathrm{HNO}_{3}$ produced in the mechanisms. More information on the wall dependent chemistry of this compound is needed before a reliable evaluation of model performance in simulating $\mathrm{HNO}_{3}$ can be made. PAN, formed from the reaction of the acyl peroxy radical $\mathrm{CH}_{3} \mathrm{C}(\mathrm{O}) \mathrm{O}_{2}$ with $\mathrm{NO}_{2}$ is formed as a second and subsequent generation product in ring-opening routes of the degradation mechanisms of methyl substituted aromatics. PAN formation is decreased in MCMv3.1 compared to MCMv3, and the peak concentrations simulated with MCMv3.1 agree with observed peak concentrations to within $50 \%$.

\subsubsection{Third group of key species: ring opened products}

The third group of key species (reaction products such as butenedial, 4-oxo-2-pentenal, $\alpha$-angelica lactone, furanones and epoxide type compounds) were measured during the EXACT campaigns by comprehensive gas chromatography (GCXGC). These measurements and their comparison with MCM simulations have been discussed by Hamilton et al. (2003). In the toluene experiments, observed products included $\alpha$-angelica lactone/4-oxo-2-pentenal as a co-eluting pair, maleic-anhydride and methyl-maleic-anhydride. E/Zhex-3-en-2,5-dione and methyl-maleic-anhydride were observed as products of $p$-xylene oxidation, and in the $1,3,5$ TMB system the two furanones, 3,5-dimethyl-3H-furanone and 3-methyl-5-methylene-5H-furan-2-one were observed. Liquid standards were used for preliminary quantification of identified compounds, and, for a number of compounds, gas phase chamber calibrations were carried out and found to be in reasonable agreement with the liquid calibrations. The comparison of the measurements with simulations using both MCMv3 and MCMv3.1 showed that the mechanism significantly over-predicts many of the measured concentrations, and while GCXGC provided positive identification of certain key intermediates, large uncertainties remain concerning the yields. In systems where organic aerosol formation is observed, a potential fate of any oxygenated product is transfer to the condensed organic phase, as discussed in more detail in relation to the MCM aromatic systems by Johnson et al. (2004a, b). Although the comparatively volatile $\alpha$ dicarbonyls, glyoxal and methylglyoxal, have been detected in aromatic SOA (Jang and Kamens, 2001), it is clear that the SOA composition is highly complex with contributions likely to be made by many products, particularly the higher molecular weight multifunctional species. In the EXACT experiments, comparatively low reagent concentrations were used such that the yields of SOA were low (ca. $6 \%$ by mass for toluene and ca. $3 \%$ by mass for the other aromatics), 
indicating that the vast majority of product (for which the total mass yield is substantially greater than $100 \%$ ) is present in the gas phase. Given that the mass yields of $\alpha$-dicarbonyls are typically $26 \%, 44 \%, 37 \%$ and $47 \%$ (for benzene, toluene $p$-xylene and 1,3,5-trimethylbenzene, respectively) it is clear that $>88 \%,>86 \%,>92 \%$ and $>94 \%$ of the $\alpha$-dicarbonyls in the respective systems would be in the gas phase even in the highly unlikely situation that the observed SOA was entirely composed of $\alpha$-dicarbonyls. Although we fully recognise and agree that it is of great importance to understand the mechanisms of SOA formation, and to identify the major contributors, we do not believe that the lack of a representation of gas-to-aerosol transfer of oxidised organic products in the present study has a major impact on the gas phase simulations in general, or on the simulated gas phase concentrations of the $\alpha$-dicarbonyls in particular.

\section{Conclusions}

Experiments have been carried out in EUPHORE to study the oxidation of benzene, toluene, $p$-xylene and 1,3,5trimethylbenzene under conditions appropriate to the atmosphere, and the large, high quality dataset obtained has been used to evaluate the performance of the MCMv3 and MCMv3.1 aromatic mechanisms. The updated mechanism, MCMv3.1, shows improved ability to simulate some of the observations from the EUPHORE dataset but significant discrepancies remain. Concerning, in particular, ozone formation potential and oxidative capacity of aromatic hydrocarbon systems:

- The peak ozone concentration in the benzene experiments is well simulated but for the substituted aromatics the simulations generally over-estimate the peak ozone concentration.

- The $\mathrm{OH}$ radical production in the mechanisms is too low to account for the $\mathrm{OH}$ concentration inferred from the rate of loss of the parent aromatic. The simulations under-estimate the oxidative capacity of the aromatic systems.

- For the majority of the experiments the simulations under-predict the NO oxidation rate, which is used as a measure of the timing of the simulations. This parameter is closely related to the processes responsible for the production of ozone and the reactivity of the system.

The combination of over-prediction of ozone concentration and under-prediction of reactivity poses a problem for mechanism development; a reduction in ozone concentration can be achieved by a reduction in peroxy radical concentration, which limits the $\mathrm{NO}$ to $\mathrm{NO}_{2}$ conversion, but this will also lead to a reduction in $\mathrm{NO}$ oxidation rate and $\mathrm{OH}$ production.
Ideas for further modifications to the mechanisms to account for the shortcomings and requirements for further laboratory and chamber experiments to investigate such ideas are discussed in the companion paper (Bloss et al., 2005).

Acknowledgements. This work was supported by the European Commission within the EXACT project, Contract No. EVK2-CT1999-00053, and by the Ministerio de Ciencia y Tecnologia within Contract No. REN2000-3277-CE/CLI. The CEAM Foundation is supported by the Generalitat Valenciana and BANCAIXA.

Edited by: W. E. Asher

\section{References}

AQS (2000): The air quality strategy for England, Scotland, Wales and Northern Ireland, Cm 4548, SE 2000/3, NIA7, Department of the Environment, Transport and the Regions, London, 2000.

Atkinson, R., Aschmann, S. M., Arey, J., and Carter, W. P. L.: Formation of ring retaining products from the $\mathrm{OH}$ radical-initiated reactions of benzene and toluene, Int. J. Chem. Kinet., 21, 801827, 1989.

Becker, K. H.: EUPHORE: Final Report to the European Commission, Contract \#EV5V-CT92-0059, Bergische Universität Wuppertal, Germany, 1996.

Bloss, C., Wagner, V., Jenkin, M. E., Bloss, W. J., Lee, J. D., Heard, D. E., Wirtz, K., Martin-Reviejo, M., and Pilling, M. J.: Development of a detailed chemical mechanism (MCMv3.1) for the atmospheric oxidation of aromatic hydrocarbons, Atmos. Chem. Phys., 5, 641-664, 2005,

SRef-ID: 1680-7324/acp/2005-5-641.

Bloss, W. J., Lee, J. D., Bloss, C., Wirtz, K., Martin-Reviejo, M., Siese, M., Heard, D. E., and Pilling, M. J.: Validation of the calibration of a laser-induced fluorescence instrument for the measurement of $\mathrm{OH}$ radicals in the atmosphere, Atmos. Chem. Phys., 4, 571-583, 2003,

SRef-ID: 1680-7324/acp/2004-4-571.

CAFE: The Clean Air for Europe (CAFE) Programme: towards a thematic strategy of air quality, Communication from the Commission, COM(2001) 245, Brussels, 2001.

Calvert, J. G., Atkinson, R., Becker, K. H., Kamens, R. M., Seinfeld, J. H., Wallington, T. J., and Yarwood, G.: The Mechanisms of Atmospheric Oxidation of Aromatic Hydrocarbons, Oxford University Press, 2002.

Carter, W. P. L.: Computer Modeling of Environmental Chamber Measurements of Maximum Incremental Reactivities of Volatile Organic-Compounds, Atmos. Envir., 29(18), 2513-2527, 1995.

Carter, W. P. L. and Lurmann, F. W.: Evaluation of a Detailed GasPhase Atmospheric Reaction-Mechanism Using Environmental Chamber Data, Atmospheric Environment Part a - General Topics, 25(12), 2771-2806, 1991.

Carter, W. P. L., Luo, D. M., Malkina, I. L., and Pierce, J. A.: Environmental chamber studies of atmospheric reactivities of volatile organic compounds, Effects of varying chamber and light source, Report to National Renewable Energy Laboratory, Contract XZ2-12075, Coordinating Research Council, Inc., Project M-9, California Air Resources Board, Contract A032-0692, and the South Coast Air Quality Management District, Contract C91323, 1995. 
Derwent, R. G., Jenkin, M. E., and Saunders, S. M.: Photochemical ozone creation potentials for a large number of reactive hydrocarbons under European conditions, Atmos. Envir., 30(2), 181-199, 1996.

Derwent, R. G., Jenkin, M. E., Saunders, S. M., and Pilling, M. J.: Photochemical ozone creation potentials for organic compounds in northwest Europe calculated with a master chemical mechanism, Atmos. Envir., 32(14-15), 2429-2441, 1998.

Dodge, M. C.: Chemical oxidant mechanisms for air quality modeling: critical review, Atmos. Envir., 34, 2103-2130, 2000.

Finlayson-Pitts, B. J. and Pitts, J. N.: Tropospheric air pollution: ozone, airborne toxics, polycyclic aromatic hydrocarbons, and particles, Science, 276, 1045-1052, 1997.

Finlayson-Pitts, B. J. and Pitts, J. N.: Chemistry of the upper and lower atmosphere: Theory, experiments and applications, San Diego, Academic Press, 1999.

Forstner, H. J. L., Flagan, R. C., and Seinfeld, J. H.: Secondary organic aerosol from the photooxidation of aromatic hydrocarbons: Molecular composition, Environ. Sci. Technol., 31(5), 13451358, 1997.

Graedler, F. and Barnes, I.: Photolysis of Z-/E-3-Hexenedione, EUPHORE Annual Report 1997, 148, 1997.

Hamilton, J. F., Lewis, A. C., Bloss, C., Wagner, V., Henderson, A. P., Golding, B. T., Wirtz, K., Martin-Reviejo, M., and Pilling, M. J.: Measurements of photo-oxidation products from the reaction of a series of alkyl-benzenes with hydroxyl radicals during EXACT using comprehensive gas chromatography, Atmos. Chem. Phys., 3, 1999-2014, 2003,

SRef-ID: 1680-7324/acp/2003-3-1999

Houweling, S. F., Dentener, F., and Lieleveld, J.: The impact of nonmethane hydrocarbon compounds on tropospheric photochemistry, J. Geophys. Res.-Atmos., 103, $10673-10696,1998$.

Jang, M. and Kamens, R. M.: Characterization of secondary aerosol from the photooxidation of toluene in the presence of NOx and 1-propene, Environ. Sci. Technol., 35, 3626-3639, 2001.

Jenkin, M. E., Saunders, S. M., and Derwent, R. G.: Photochemical Ozone Creation Potentials for Aromatic Hydrocarbons: Sensitivity to Variations in Kinetic and Mechanistic Parameters, Chemical Behaviour of Aromatic hydrocarbons in the Troposphere, Valencia, Spain, 81-87, 2000.

Jenkin, M. E., Saunders, S. M., Wagner, V., and Pilling, M. J.: Protocol for the development of the Master Chemical Mechanism, MCMv3 (Part B): tropospheric degradation of aromatic volatile organic compounds, Atmos. Chem. Phys., 3, 181-193, 2003,

SRef-ID: 1680-7324/acp/2003-3-181.

Johnson, D., Jenkin, M. E., Wirtz, K., and Martin-Reviejo, M.: Simulating the Formation of Secondary Organic Aerosol from the Photooxidation of Toluene, Environmental Chemistry, 1, 150 165, 2004.

Johnson, D., Jenkin, M. E., Wirtz, K., and Martin-Reviejo, M.: Simulating the Formation of Secondary Organic Aerosol from the Photooxidation of Aromatic Hydrocarbons, Environmental Chemistry, in press, 2004.
Killus, J. P. and Whitten, G. Z.: Backgroud reactivity in smog chambers, Int. J. Chem. Kinet., 22, 547-575, 1990.

Klotz, B., Sorensen, S., Barnes, I., Becker, K. H., Etzkorn, T., Volkamer, R., Platt, U., Wirtz, K., and Martin-Reviejo, M.: Atmospheric oxidation of toluene in a large-volume outdoor photoreactor: In situ determination of ring-retaining product yields, J. Phys. Chem. A, 102(50), 10 289-10 299, 1998.

Liang, J. and Jacobson, M. Z.: Compariosn of a 4000 reaction chemical mechanism with the carbon bond IV and an adjusted carbon bond IV-EX mechanism using SMVGEAR II., Atmos. Envir., 34, 3015-3026, 2000.

Olariu, R. I., Klotz, B., Barnes, I., Becker, K. H., and Mocanu, R.: FT-IR study of the ring-retaining products from the reaction of $\mathrm{OH}$ radicals with phenol, o-, m-, and p-cresol, Atmos. Envir., 36(22), 3685-3697, 2002.

PORG: Ozone in the United Kingdom, Report prepared by the UK Photochemical Oxidants Review Group, London, HMSO Publications, 1997.

Smith, D. F., McIver, C. D., and Kleindienst, T. E.: Primary product distribution from the reaction of hydroxyl radicals with toluene at ppb NOX mixing ratios, J. Atmos. Chem., 30(2), 209-228, 1998.

Smith, D. F., Kleindienst, T. E., and McIver, C. D.: Primary product distributions from the reaction of $\mathrm{OH}$ with m-, p-xylene, 1,2,4and 1,3,5-trimethylbenzene, J. Atmos. Chem., 34(3), 339-364, 1999.

Solomon, P., Cowling, E., Hidy, G., and Furiness, C.: Comparison of scientific findings from major ozone field studies in North America and Europe, Atmos. Envir., 34(12-14), 1885-1920, 2000.

Thuener, L. P., Rea, G., and Wenger, J.: Photolysis of butenedial and 4-oxo-2-pentenal, EUPHORE Annual Report 2001, 2003.

Tuazon, E. C., Atkinson, R., Plum, C. N., Winer, A. M., and Pitts, J. N.: The Reaction of Gas-Phase N205 with Water-Vapor, Geophys. Res. Lett., 10(10), 953-956, 1983.

Volkamer, R., Platt, U., and Wirtz, K.: Primary and secondary glyoxal formation from aromatics: Experimental evidence for the bicycloalkyl-radical pathway from benzene, toluene, and pxylene, J. Phys. Chem. A, 105(33), 7865-7874, 2001.

Volkamer, R., Klotz, B., Barnes, I., Imamura, T., Wirtz, K., Washida, N., Becker, K. H., and Platt, U.: OH-initiated oxidation of benzene - Part I. Phenol formation under atmospheric conditions, Phys. Chem. Chem. Phys., 4(9), 1598-1610, 2002.

Wagner, V., Jenkin, M. E., Saunders, S. M., Stanton, J., Wirtz, K., and Pilling, M. J.: Modelling of the photooxidation of Toluene: conceptual ideas for validating detailed mechanisms, Atmos. Chem. Phys., 3, 89-106, 2003,

\section{SRef-ID: 1680-7324/acp/2003-3-89.}

Zádor, J., Wagner, V., Wirtz, K., and Pilling, M. J.: Quantitative assessment of uncertainties for a model of tropospheric ethene oxidation using the European Photochemical Reactor, Atmos. Envir., in press, 2004. 